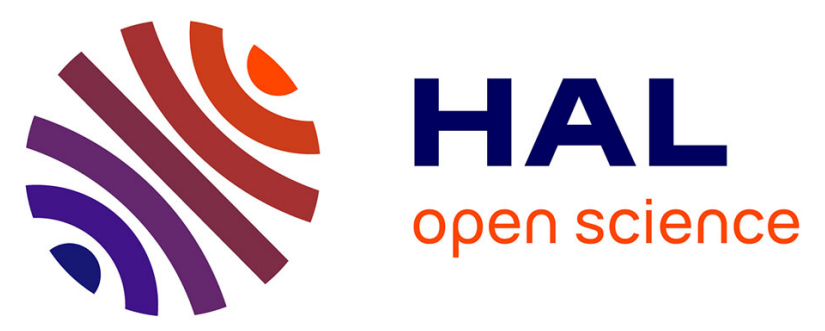

\title{
Probing structural transitions in both structured and disordered proteins using site-directed spin-labeling EPR spectroscopy
}

Sonia Longhi, Valérie Belle, André Fournel, Bruno Guigliarelli, Frédéric

Carrière

\section{To cite this version:}

Sonia Longhi, Valérie Belle, André Fournel, Bruno Guigliarelli, Frédéric Carrière. Probing structural transitions in both structured and disordered proteins using site-directed spin-labeling EPR spectroscopy. Journal of Peptide Science, 2011, 17 (5), pp.315-328. 10.1002/psc.1344 • hal-03555670

\author{
HAL Id: hal-03555670 \\ https://hal.science/hal-03555670
}

Submitted on 3 Feb 2022

HAL is a multi-disciplinary open access archive for the deposit and dissemination of scientific research documents, whether they are published or not. The documents may come from teaching and research institutions in France or abroad, or from public or private research centers.
L'archive ouverte pluridisciplinaire $\mathbf{H A L}$, est destinée au dépôt et à la diffusion de documents scientifiques de niveau recherche, publiés ou non, émanant des établissements d'enseignement et de recherche français ou étrangers, des laboratoires publics ou privés. 


\title{
Probing structural transitions in both structured and disordered proteins using site-directed spin-labeling EPR spectroscopy ${ }^{\ddagger}$
}

\author{
Sonia Longhi, ${ }^{a *}$ Valérie Belle, ${ }^{b}$ André Fournel, ${ }^{b}$ Bruno Guigliarelli ${ }^{b}$ \\ and Frédéric Carrière ${ }^{\mathrm{c} *}$
}

EPR spectroscopy is a technique that specifically detects unpaired electrons. EPR-sensitive reporter groups (spin labels or spin probes) can be introduced into biological systems via site-directed spin-labeling (SDSL). The basic strategy of SDSL involves the introduction of a paramagnetic group at a selected protein site. This is usually accomplished by cysteine-substitution mutagenesis, followed by covalent modification of the unique sulfydryl group with a selective reagent bearing a nitroxide radical. In this review we briefly describe the theoretical principles of this well-established approach and illustrate how we successfully applied it to investigate structural transitions in both human pancreatic lipase (HPL), a protein with a well-defined $\alpha / \beta$ hydrolase fold, and the intrinsically disordered C-terminal domain of the measles virus nucleoprotein ( $N_{T A I L}$ ) upon addition of ligands and/or protein partners. In both cases, SDSL EPR spectroscopy allowed us to document protein conformational changes at the residue level. The studies herein summarized show that this approach is not only particularly well-suited to study IDPs that inherently escape atomistic description by X-ray crystallography but also provides dynamic information on structural transitions occurring within well-characterized structured proteins for which X-ray crystallography can only provide snapshots of the initial and final stages. Copyright (c) 2011 European Peptide Society and John Wiley \& Sons, Ltd.

Keywords: site-directed spin labeling; EPR spectroscopy; protein structural transitions; human pancreatic lipase; lid opening; intrinsic disorder; induced folding; disorder-to-order transitions; measles virus; nucleoprotein; phosphoprotein

\section{Introduction to SDSL-EPR Spectroscopy}

EPR spectroscopy is a technique that specifically detects unpaired electrons. It is based on the observation of the energy absorbed by a paramagnetic system in a magnetic field. In biological systems, these centers are mainly free radicals or some ions of transition metals such as iron, copper, and nickel. SDSL combined with EPR is a powerful technique for detecting structural changes in proteins that are devoid of such paramagnetic centers. The basic strategy of SDSL involves the insertion of a paramagnetic label at a selected site of a protein and its observation by EPR spectroscopy (for reviews see [1-8]). This is usually accomplished by cysteinesubstitution mutagenesis, followed by covalent modification of the sulfydryl group with a selective nitroxide reagent, such as the MTSL (Figure 1). Since the pioneering works of the group of Hubbell $[9,10]$, SDSL EPR spectroscopy has emerged as a valuable tool for studying structural characteristics in a wide range of proteins. Several EPR approaches can be used to study labeled proteins and to obtain information on the side chain mobility of the nitroxide probe and its solvent accessibility, as well as on distances between two intra- or intermolecular spin probes. In particular, the combination of these different approaches has been extensively used to study conformational changes arising from either protein-substrate, protein-ligand interactions or light irradiation [4,11-16]. The recent development of pulse EPR [17], in particular combined with DEER techniques (4-pulses DEER sequence [18]) allows determination of inter-spin distances in the range of $1.8-8.0 \mathrm{~nm}$, thus covering a wide range of interest for the study of large conformational transitions and biomolecule associations. The method is based on the introduction of two spin probes and the distance between them is determined through spin-spin dipolar interaction analyses $[19,20]$. This technique has

* Correspondence to: Sonia Longhi, AFMB, UMR 6098,163, Avenue de Luminy, Case 932, 13288 Marseille Cedex 09, France.E-mail:Sonia.Longhi@afmb.univmrs.fr

** Frédéric Carrière, EIPL, UPR 9025 CNRS and Aix-Marseille Université, 31 Chemin Joseph Aiguier, 13402MarseilleCedex, France.E-mail: carriere@ifr88.cnrs-mrs.fr

a Architecture et Fonction des Macromolécules Biologiques, UMR 6098 CNRS and Aix-Marseille Université, 163 Avenue de Luminy, Case 932, 13288 Marseille Cedex 09, France

b Bioénergétique et Ingénierie des Protéines, UPR 9036 CNRS and Aix-Marseille Université, 31 Chemin Joseph Aiguier, 13402 Marseille Cedex, France

c CNRS and Aix-Marseille Université, Enzymologie Interfaciale et Physiologie de la Lipolyse, UPR 9025, 31 Chemin Joseph Aiguier, 13402 Marseille Cedex, France

₹ Special issue devoted to contributions presented at the 12th Naples Worshop on Bioactive Peptides and 2nd Italy-Korea Symposium on Antimicrobial Peptides, 4-7 June 2010, Naples, Italy.

Abbreviations used: EPR, electron paramagnetic resonance; SDSL, site-directed spin labeling, MTSL, (1-oxyl-2,2,5,5-tetramethyl- ${ }^{3}$-pyrroline-3methyl) methanethiosulfonate; HPL, human pancreaticlipase; $N_{\text {TAIL }} C$-terminal domain of the nucleoprotein; E600, diethyl p-nitrophenyl phosphate; NaTDC, sodium taurodeoxycholate; CMC, critical micellar concentration; FTIR, Fourier transform infrared spectroscopy; DEER, double electron-electron resonance; $I D P$, intrinsically disordered protein; $M e V$, measles virus; $N$, nucleoprotein; $P$, phosphoprotein; $X D, X$ domain of $P, M o R E$, molecular recognition element, SAXS, small angle $X$-ray scattering; TFE, 2,2,2-trifluoroethanol; CD, circular dichroism; NMR, nuclear magnetic resonance; HSQC, heteronuclear single quantum coherence; $D T ;$ dithiothreitol. 


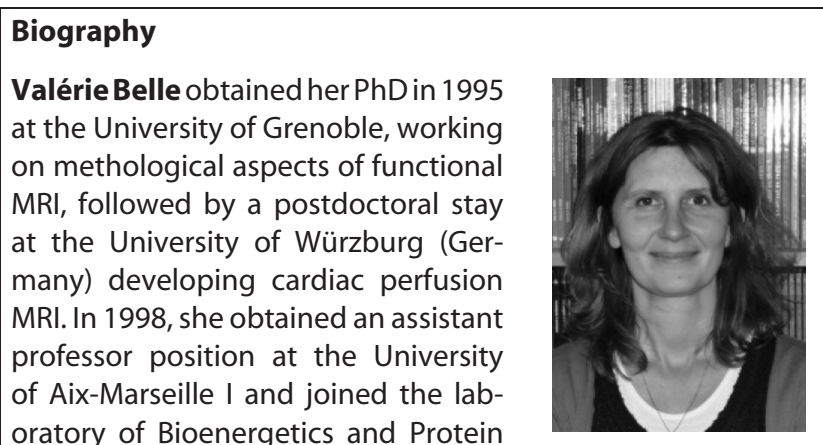
oratory of Bioenergetics and Protein Engineering. She worked on the characterization of metalloenzymes by means of EPR spectroscopy. In the last few years she focused her research activities on the study of structural transitions in proteins by a site directed spin labeling (SDSL) combined to EPR spectroscopy.

André Fournel obtained his phD in 1970 at the University of Montpellier II, working on solid state optics. He spent several years as physics lecturer in different universities (Montpellier, Tunis, Marseille). In 1988, he became assistant professor at the University of Aix Marseille I, where he worked on solid state electronics, a research field that was the subject of his "thèse

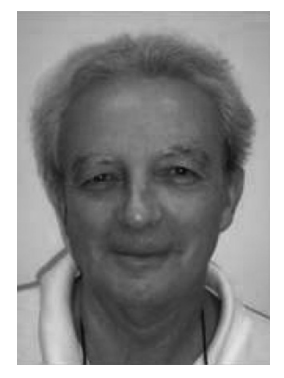
d'état" ( $2^{\text {nd }}$ thesis) obtained in 1991. In 1993, he reoriented his research activities on EPR spectroscopy applied to the study of biomolecules and joined the laboratory of Bioenergetics and Protein Engineering. In the last few years, he developed the use of paramagnetic probes to study of structural transitions in proteins.

Frederic Carriere is Director of Research at entre tational de ta Recherche Scientifique (CNRS) and Director of the Laboratory of Enzymology at Interfaces and Physiology of Lipolysis (EIPL UPR9025, Marseille, France). He received a degree in Chemical Engineering from Marseille High School of Chemistry in 1986 and a PhD in Enzymology from Aix-Marseille University

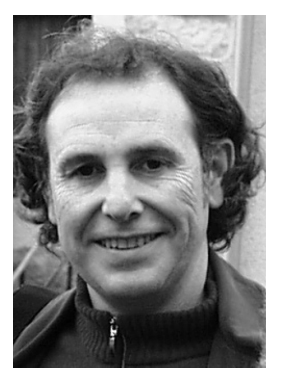
in 1992. From 1988 to 1992 , he prepared his PhD thesis in the laboratory of Dr. Robert Verger, on the biochemical properties and the physiological role of gastric lipase. From 1992 to 1994, he was researcher at Novo Nordisk (Denmark) where he worked on the structure-function relationships of pancreatic lipases in the group of Dr. Lars Thim. He obtained a permanent position at CNRS in 1995 and was group leader at Dr. Robert Verger's laboratory before becoming his successor in 2004. Frédéric Carrière has 20 years of expertise in the field of lipolytic enzymes and 120 publications dealing with the structure-function relationships and physiological roles of digestive lipases (visit his web site at http://eipl.cnrs-mrs.fr/).

\section{Biography}

Bruno Guigliarelli, 50 years old, is Professor in Physics at the University of Aix-Marseille 1 and Director of the Laboratory of Bioenergetics and Protein Engineering of CNRS (BIP). Within the BIP, he manages the group of Biophysics of Metalloproteins and develops the applications of EPR spectroscopy to structural and functional studies of complex enzyme systems

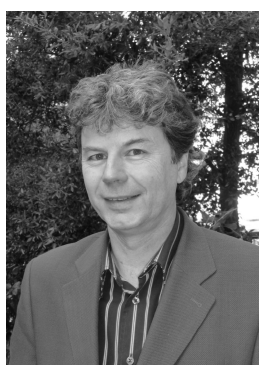
since the mid $80^{\prime} \mathrm{s}$. His research activity concerns oxidoreductases involved in energy metabolism in prokaryotes, electron and proton transfer mechanisms, and more recently the biostructural applications of spin-labeling. He has authored 110 publications (2300 citations), 2 books, and supervised $10 \mathrm{PhD}$ theses. He is currently the President of the French EPR Society (ARPE) and coordinator of the Multidisciplinary EPR Center of Aix-Marseille.

Sonia Longhi is Director of Research at the Center for the National Scientific Research (CNRS), heading the "Structural Disorder and Molecular Recognition" group within the AFMB laboratory. She obtained a PhD in molecular biology from the Universitá degli Studi of Milan in 1993. She got a HDR in structural virology from the University of Aix-Marseille I in 2003. Her scientific

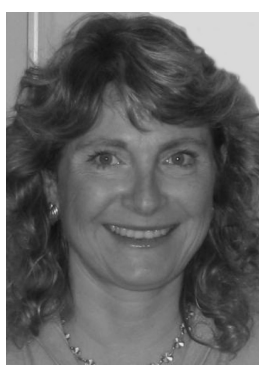
focus is on intrinsically disordered proteins (IDPs) and the mechanistic and functional aspects of the interactions they establish with partners. She has authored more than sixty scientific publications, edited a book on measles virus nucleoprotein and co-edited (with Prof. Vladimir Uversky) a book on the experimental approaches to characterize IDPs and the folding coupled to binding events they undergo in the presence of partners.

been applied to a wide range of biological structural systems [21-26].

In the following, we describe the basics of nitroxide EPR spectral shapes with respect to spin label mobility and the means to extract semi-quantitative parameters from these shapes.

Nitroxide radicals are anisotropic paramagnetic centers characterized by the interaction between an electronic spin $S=1 / 2$ and a nuclear spin $\mathrm{I}=1$ arising from the magnetism of the ${ }^{14} \mathrm{~N}$ nucleus located in the vicinity of the unpaired electron. The anisotropy of both $\mathrm{g}$ tensor (Zeeman interaction) and A tensor (hyperfine interaction) makes EPR spectra critically dependent on the mobility of the radical. Figure 2 shows a set of characteristic EPR spectra, simulated by the EasySpin software [27], for various motional regimes, differing in their rotational correlation time $\tau_{r}$. When these radicals are allowed to tumble rapidly in an isotropic way, as in the case of a liquid, magnetic interactions ( $\mathrm{g}$ and $\mathrm{A}$ tensors) are completely averaged and the EPR spectrum displays three narrow lines (see spectrum $A$ in Figure 2). As the motion becomes progressively slower, the magnetic anisotropy is no longer totally averaged. As long as the correlation time $\tau_{r}$ is in the nanosecond timescale, it results in a differential broadening of lines in the spectrum, while line positions remain constant (see spectrum B in Figure 2). This is the so-called fast motional regime, valid until $\tau_{r}=10^{-9} \mathrm{~s}$. For values 


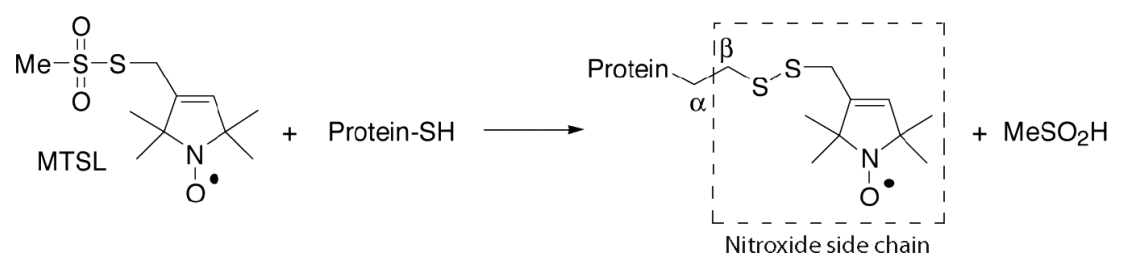

Figure 1. MTSL chemical structure and covalent modification of the SH group of a cysteine.

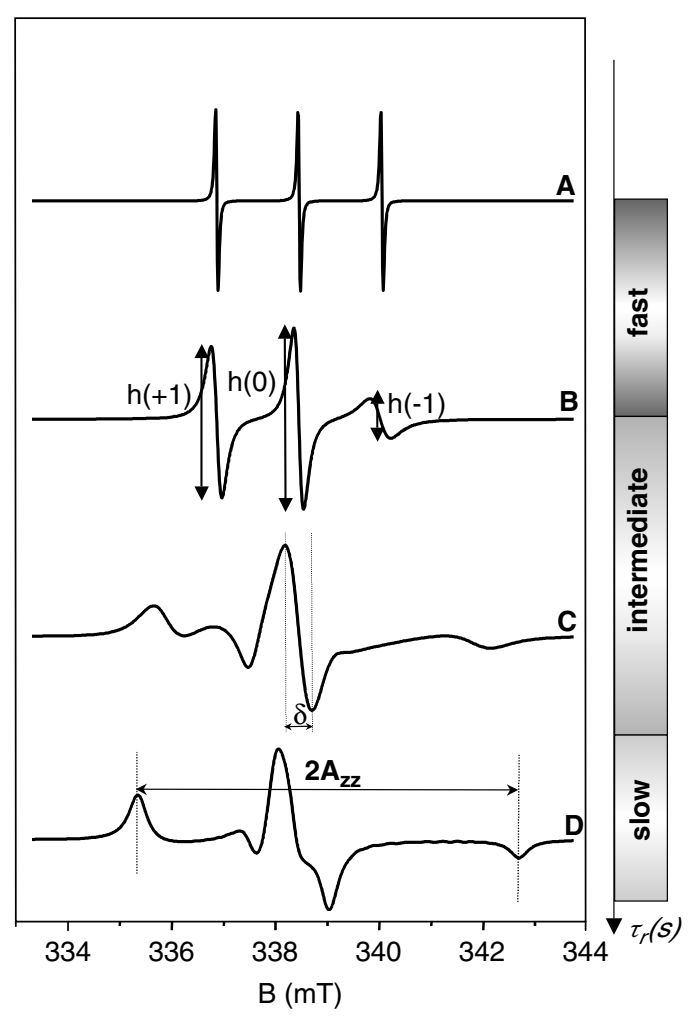

Figure 2. Set of various simulated EPR spectra, using EasySpin software [27], of a nitroxide radical corresponding to different isotropic motional regimes characterized by various rotational correlation times $\tau_{r}\left(1.10^{-12} \mathrm{~s}\right.$ (A); $\left.1.10^{-9} \mathrm{~s}(\mathrm{~B}) ; 1.10^{-8} \mathrm{~s}(\mathrm{C}) ; 1.10^{-5} \mathrm{~s}(\mathrm{D})\right)$. The different semi-quantitative parameters used to characterize the spectra are represented (see text for details): the amplitude of the derivative lines (B), the width of the central line $\delta(C)$ and the outer line splitting $2 \mathrm{~A}_{\mathrm{zz}}, \mathrm{A}_{\mathrm{zz}}$ being the $\mathrm{z}$-component of the hyperfine tensor (D). Note that in the simulation, we did not take into account the contribution of the ${ }^{13} \mathrm{C}$ lines (i.e. natural abundance of ${ }^{13} \mathrm{C}$ ).

of $\tau_{r}>10^{-9} s$ up to $10^{-6} s$, the averaging of the magnetic interactions ( $\mathrm{g}$ and $\mathrm{A}$ tensors) becomes less and less efficient, leading to shape distortions of the EPR spectrum (see spectrum C in Figure 2). This range of $\tau_{r}$ values defines the intermediate motional regime. When $\tau_{r}$ becomes superior to $10^{-6} s$, the slow motional regime is reached, and the full effects of the anisotropy of the magnetic interactions ( $g$ and A tensors) are observed. In this case, the EPR spectrum corresponds to the one obtained from a frozen solution of the spin label (see spectrum D in Figure 2).

When grafted onto proteins, nitroxide spin labels give rise to EPR spectra whose shape reflects the spin label mobility. Any change in this environment resulting from either a physical or chemical event can then be identified from the change in the EPR signature. Notably, EPR spectra of spin-labeled proteins can be recorded at room temperature, thus providing information on the local environment of the spin label under conditions close to the physiological ones.

The mobility of a spin label grafted onto a protein is due to the movement of the entire protein ( $\left.\tau_{\text {prot }}\right)$ and to an ensemble of different local movements $\left(\tau_{\text {local }}\right)$ including local backbone fluctuations and internal dynamics of the spin-labeled side chain. The influence of the movement of the entire protein on the EPR spectra is negligible when the rotational correlation time of the protein $\left(\tau_{\text {prot }}\right)$ is much greater than $\tau_{\text {local }}$. This is the case for a protein with a molar mass $\geq 50 \mathrm{kDa}$ ( $\tau_{\text {prot }}>20 \mathrm{nsec}$ ) and when $\tau_{\text {local }}$ is in the nanosecond timescale. For smaller proteins, the influence of the movement can be reduced by increasing the viscosity of the solution by adding up to $30 \% \mathrm{w} / \mathrm{v}$ sucrose. This induces an increase of $\tau_{\text {prot }}$ by a factor of about three, while $\tau_{\text {local }}$ remains unchanged [28].

How can mobility information be extracted from EPR spectra? One way to process the data in a quantitative way is to simulate EPR spectra, an approach developed by Freed and coworkers [29,30]. Besides the simulation method, semi-quantitative analyses can be used, consisting in measuring in EPR spectra a parameter that directly depends on the mobility of the spin label.

In the fast motional regime of the spin label $\left(10^{-11}<\tau_{\text {local }}<\right.$ $\left.10^{-9} \mathrm{~s}\right)$, the parameter of choice is the ratio between the peak-topeak amplitude of the lateral lines arising from the different spin states of the nitroxide ${ }^{14} \mathrm{~N}$ nucleus, referred to as $h\left(M_{l}=+1\right)$ or $h\left(M_{l}=-1\right)$, and that of the central line, referred to as $h\left(M_{l}=0\right)$ (Figure 2). For a fast anisotropic motion, the $h(+1) / h(0)$ ratio was found to be a more sensitive parameter than the $h(-1) / h(0)$ ratio, as shown from analysis of the variation of these ratios from a set of simulated spectra as a function of typical rotational correlation times [31].

Another parameter that is sensitive to label motion is the socalled 'scaled mobility' that has been introduced by Hubbell and co-workers [4]. It is based on the measurement of the peak-topeak width of the central line $\delta$ (Figure 2). This parameter is well suited when the study involves a collection of spin labels grafted individually on a protein and has the advantage of being not restricted to a particular regime of mobility. On the other hand, in the intermediate/slow motional regime of the spin label, the outer line splitting $2 \mathrm{~A}_{\mathrm{zz}}$ is a well-suited and sensitive parameter (Figure 2).

\section{Using SDSL-EPR Spectroscopy to Monitor Con- formational Changes within Proteins}

In 1996, Mchaourab and co-workers established the basis for the interpretation of the EPR line shape of spin labels grafted on proteins by investigating the relationship between the mobility of the nitroxide side chain and the structure of T4 lysozyme and showed that the mobility of the spin labels grafted 
reflects backbone fluctuations as well as the protein tertiary structure [32]. Since these pioneering studies, the importance of backbone fluctuations and of tertiary contacts on EPR spectra has been studied in more detail using a collection of nitroxide methanethiosulfonate reagents [33,34].

In this review we summarize the main findings resulting from the application of SDSL EPR spectroscopy to the study of structural transitions within the $\mathrm{HPL}_{\lambda}$ and the intrinsically disordered Cterminal domain of the measles virus nucleoprotein $\left(\mathrm{N}_{\mathrm{TAIL}}\right)$, two well-characterized proteins for which a wealth of biochemical and structural data are available.

\section{Application of SDSL EPR Spectroscopy to the Study of Structural Transitions within HPL}

$X$-ray crystallography studies on HPL have shown that this enzyme consists of a catalytic $N$-terminal domain with an $\alpha / \beta$ hydrolase fold and of a $\beta$-sandwich $C$-terminal domain [35-37]. The active site in the $\mathrm{N}$-terminal domain comprises a ser-his-asp catalytic triad, and its access is controlled by a lid adopting two different conformations (referred to as 'open' and 'closed'). The C-terminal domain is required for the interaction with a lipid-water interface [38], as well as for binding to colipase, a physiological cofactor required for the adsorption of the lipase at a lipid-water interface in the presence of competing amphiphiles such as bile salts [39]. When the HPL-colipase complex was crystallized in the presence of bile salts and phospholipids, the lid was observed in the open conformation, thus giving free access to the active site. The $N$ terminal part of colipase was also found to interact with the lid domain, thus forming a second lipase-colipase interaction site. On the basis of these structural findings, it was suggested that colipase may help to bring the catalytic $N$-terminal domain of pancreatic lipase into close contact with the lipid interface, where a drastic change occurs in the conformation of the lid.

Although X-ray crystallography is a powerful technique, it mainly yields static information. The closed and open conformations of HPL observed in the crystal structures are thought to correspond to the initial and final stages of the opening of the lid. However, the opening of the lid can be anticipated to be a complex process probably involving several steps and implying different, intermediate conformations, as in the case of the lipase from Thermomyces lanuginosus [40]. How and when the lid opens has long been a matter of discussion, although a few studies have indicated that the lid may be open in solution in the presence of bile salts and colipase [41-44]. The presence of a lipid-water interface would not be strictly required to induce and stabilize the open conformation of the lid, with this latter being stabilized in solution by interactions with both bile salt micelles and colipase [43]. Inhibition studies have shown, however, that the sole presence of bile salts suffices to induce a fast inactivation of pancreatic lipase, probably via the opening of the lid that normally prevents the access of inhibitors to the active site in solution [45].

In view of achieving a dynamic description of the opening of the lid, as well as to unveil the possible coexistence of several lid conformations, a paramagnetic probe was covalently bound to the lid of HPL. EPR spectroscopy was then used to monitor the conformational change occurring in the lid in solution in the presence of its physiological partners, namely colipase and bile salts.

To this endeavor, we targeted for cysteine substitution and ensuing spin-labeling residue D249, a residue of the lid whose side chain is fully exposed to solvent in both the open and closed conformations and that is not involved in any interactions with the

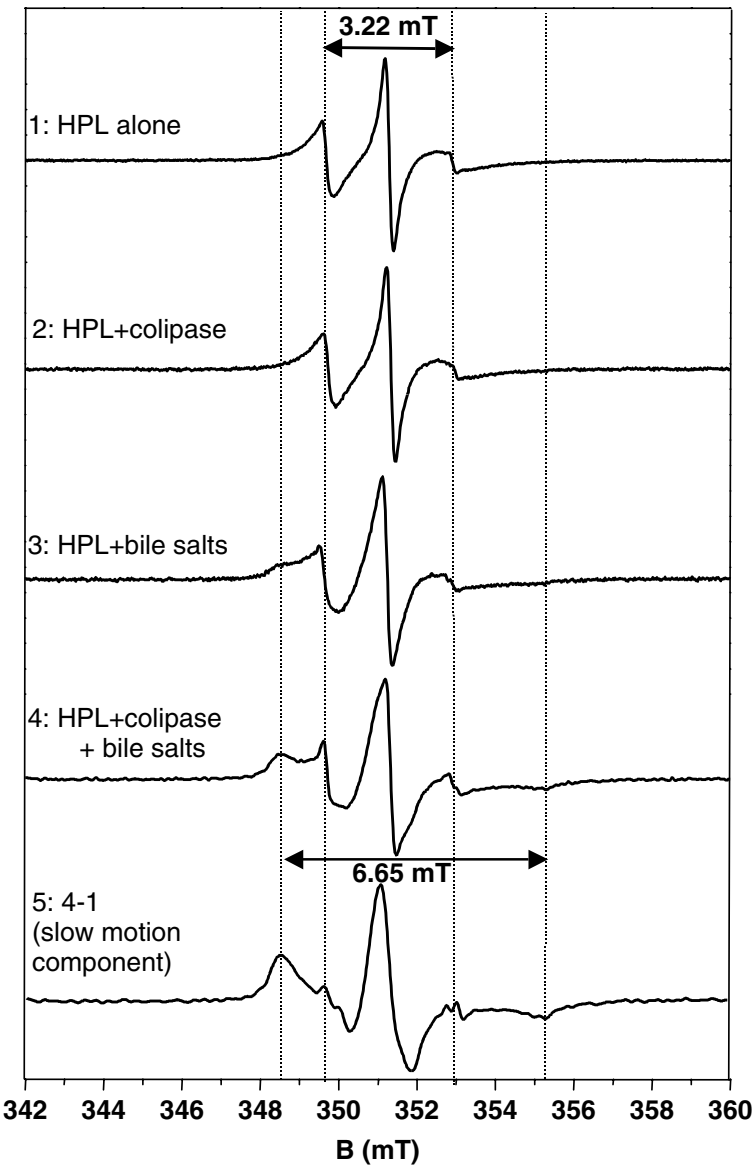

Figure 3. EPR spectra of spin-labeled D249C-C181Y HPL variant (80 $\mu \mathrm{M})$ recorded at room temperature on an ESP 300E Bruker spectrometer equipped with an ELEXSYS Super High Sensitivity resonator operating at $9.9 \mathrm{GHz}$. The microwave power was $10 \mathrm{~mW}$ and the magnetic field modulation frequency and amplitude were $100 \mathrm{kHz}$ and $0.1 \mathrm{mT}$, respectively. The EPR spectra of spin-labeled HPL variant in the absence or presence of colipase either with or without $4 \mathrm{mM} \mathrm{NaTDC}$ are shown. The difference spectrum (bottom) obtained by subtracting the spectrum of HPL alone from the composite spectrum obtained in the presence of colipase and $4 \mathrm{mM} \mathrm{NaTDC}$ is also shown. The horizontal arrows indicate the outer line splitting of the two spectral components.

lipase core or the colipase according to the crystal structures [46]. In order to ensure specific spin labeling at a single position, the other accessible free cysteine, namely C181 [47,48], was substituted by a tyrosine, as observed at the equivalent position in other pancreatic lipases $[49,50]$. The double C181Y-D249C HPL variant (hereafter referred to as HPL variant) was produced in the yeast Pichia pastoris and purified to homogeneity in a single cation exchange chromatography step. A DTT reduction step prior to spin labeling turned out to be crucial to ensure reduction of the oxydized cysteine(s) and to lead to high (i.e. approximately $80 \%$ ) labeling yields [46].

The HPL variant, irrespective of the presence or absence of the spin label, was found to have the same kinetic properties as native HPL and was shown to be inhibited by E600 only in the presence of micellar concentrations of bile salts, like in the case of native HPL [46].

The EPR spectrum of the spin-labeled HPL variant (see spectrum 1 in Figure 3) showed a relatively narrow single-component shape, with an outer line splitting of $3.22 \pm 0.02 \mathrm{mT}$, indicating a fairly fast motion of the radical typical of a solvent-exposed location [32]. 


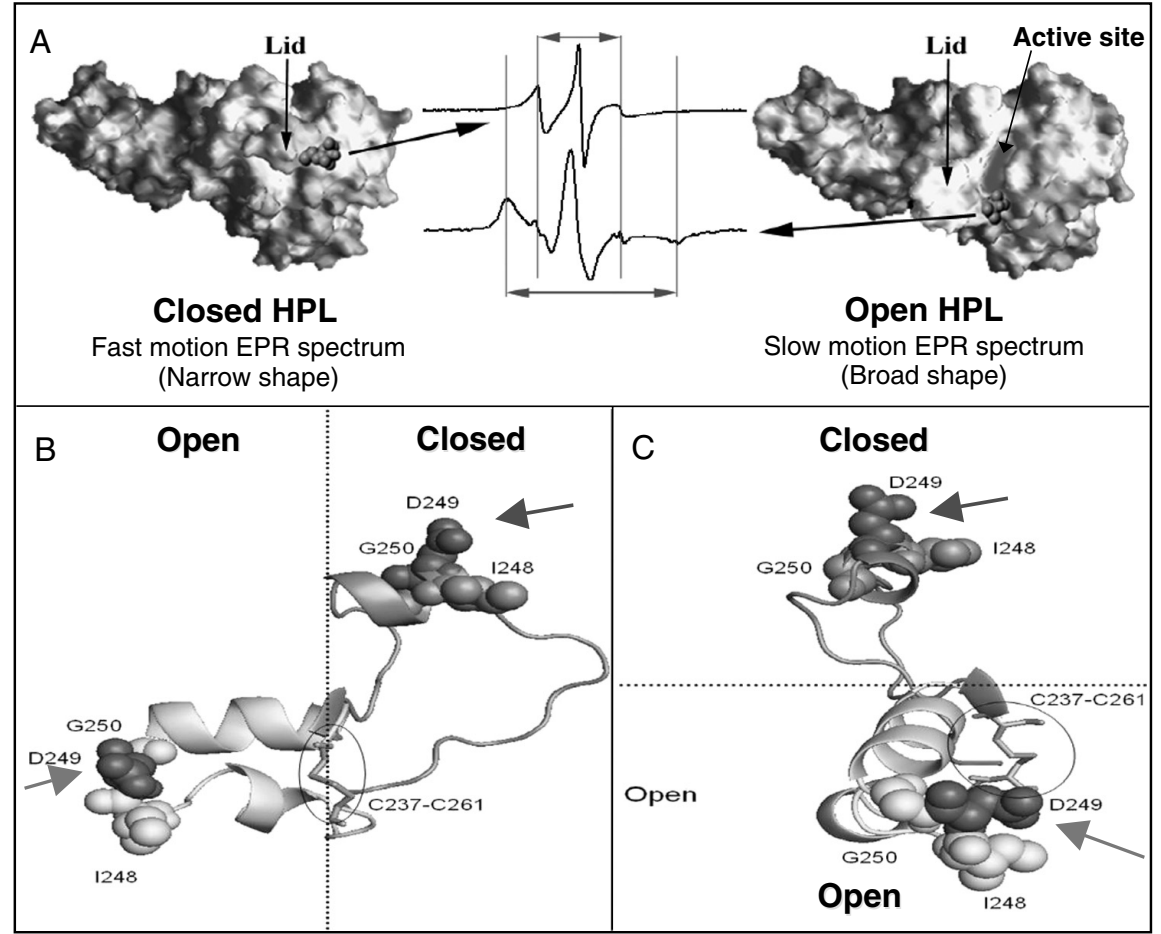

Figure 4. (A) Molecular surface representation of HPL in its closed (pdb code 1N8S) [36] and open (pdb code 1LPA) [37] conformations. Hydrophobic and polar surfaces are shown in white and gray, respectively. Residue 249 targeted for cysteine substitution and spin labeling is shown in space-filling model. The EPR spectra of the spin-labeled closed or open forms of HPL are shown. (B) and (C) Ribbon representation of the open and closed conformations of the lid showing the environment of residue 249. The 237-261 region of HPL is shown in the form of a ribbon model. The disulfide bridge between C237 and C261 is shown in sticks, whereas residues I248, D249 and G250 are shown in space-filling CPK. Panel C is the left side view corresponding to the view in Panel B. The picture was drawn using PyMOL (DeLano Scientific, San Carlos, CA; http://www.pymol.org) [51].

While addition of a two-fold molar excess of colipase did not induce any change in the EPR spectrum (see spectrum 2 in Figure 3), the presence of $4 \mathrm{mM}$ bile salts gave rise to a composite spectrum (see spectrum 3 in Figure 3 ) consisting of two components showing different mobilities of the nitroxide radical: one with a relatively narrow spectral shape with an outer line splitting of $3.22 \pm 0.02$ $\mathrm{mT}$ (hereafter referred to as the fast-motion component), and one with a very broad spectral shape reflecting a highly restricted mobility of the radical as indicated by its outer line splitting of $6.65 \pm 0.05 \mathrm{mT}$. This shape will be hereafter referred to as the slow-motion component. When both physiological partners were present, the proportion of the slow-motion component increased strongly (see spectrum 4 in Figure 3). In order to isolate the slowmotion component we subtracted the fast-motion component (see spectrum 1 in Figure 3) from the composite spectrum. The resulting spectrum (see spectrum 5 in Figure 3 ) is representative of a radical with a very restricted mobility suggesting a location at a site poorly accessible to the solvent [32]. The proportion of the slow-motion component in composite spectra was quantitatively estimated from the integrated intensities of the absorption line.

The assignment of the EPR spectrum components to HPL lid conformations was based on experiments with E600. After addition of the E600 inhibitor to the spin-labeled HPL variant in the absence of bile salts and colipase, the rate of lipase inhibition was extremely slow (no access of the inhibitor to the active site) and the EPR spectrum remained mainly composed of a fast-motion component [46]. When the experiments were performed in the presence of micellar concentrations (2-4 mM) of NaTDC and colipase, the inhibition rate increased significantly and the EPR spectrum was mainly (i.e. $80 \%$ ) composed of a slow-motion component.
Subsequent dilution of the samples aimed at reducing bile salt concentration below the $\mathrm{CMC}$, did not give rise to any spectral changes, whereas similar experiments performed in the absence of E600 allowed to restore an EPR spectrum mainly composed of a fast-motion component. As the closed conformation of HPL lid is not compatible with the presence of $\mathrm{E} 600$ covalently linked to the active serine of $\mathrm{HPL}$, these results allowed unambiguous assignment of the fast-motion and slow-motion components to the closed and open form of $\mathrm{HPL}$, respectively (Figure $4 \mathrm{~A}$ ). In addition, the experiments without E600 showed that the lid opening is a reversible process. These conclusions are supported by the analysis of the 3D structures of HPL showing that the side chain of residue 249 onto which the spin label is grafted is more constrained in the open form than in the closed form of HPL (Figure 4B,C). In addition, when the kinetics of reduction of the spin-labeled HPL variant in the presence of an excess of DTT was studied, the fast-motion component of the EPR spectrum in the absence of bile salts and colipase was found to disappear immediately after addition of DTT and to be totally converted into a signal of unbound, free-rotating radical in solution [46]. On the other hand, the slow-motion component of the EPR spectrum obtained in the presence of bile salts and colipase remained unchanged up to $30 \mathrm{~min}$ after the reduction reaction was started [46]. These data are consistent with the spin label being less accessible to the solvent in the open form of HPL than in the closed form.

The effects of the bile salt concentration on the spectral shapes were studied by recording the EPR spectra of the spin-labeled HPL variant in solution, in either the absence or the presence of a two-fold molar excess of colipase (Figure 5) [46]. In the 

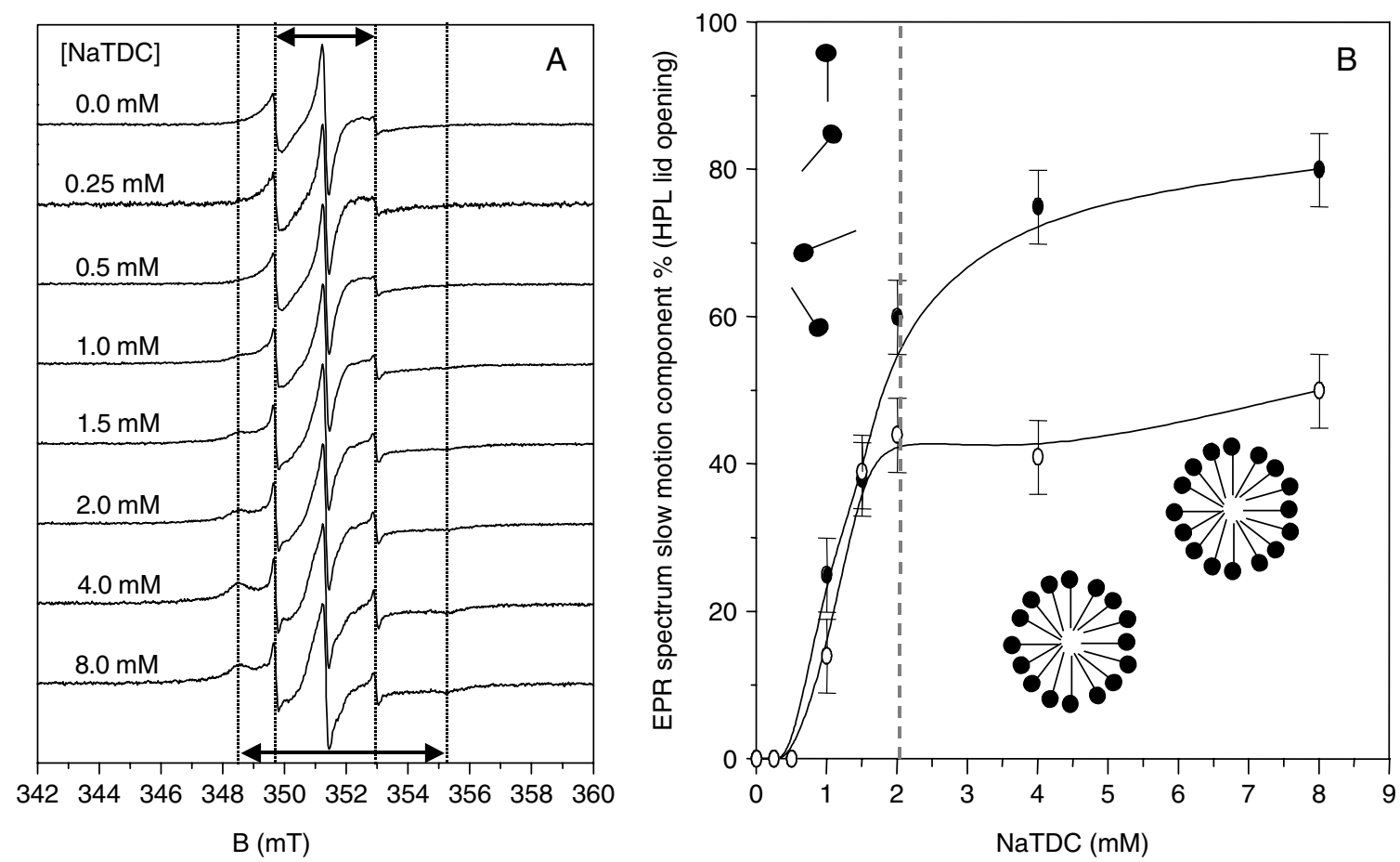

Figure 5. (A) Normalized room temperature EPR spectra of the spin-labeled D249C-C181Y HPL variant ( $80 \mu \mathrm{M})$ as a function of NaTDC concentration. The dotted vertical lines point the outer line splitting. (B) Proportion of the EPR spectrum slow-motion component at the different NaTDC concentrations. Open circles: experiments performed in the absence of colipase. Full circles: experiments performed with a two-fold molar excess of colipase. The standard deviation of the relative proportions of the slow-motion component, due to both errors of subtraction and integrated intensity measurements, was estimated to be $\pm 8 \%$. EPR spectra were recorded at $9.9 \mathrm{GHz}$ with a microwave power of $10 \mathrm{~mW}$, with a magnetic field modulation frequency of $100 \mathrm{kHz}$ and an amplitude of $0.1 \mathrm{mT}$. The dashed vertical line represents the CMC.

absence of colipase and up to $0.5 \mathrm{mMNaTDC}$, the shape of the EPR spectrum remained unchanged. Above $1 \mathrm{mMNaTDC}$, however, the proportion of the slow-motion component quickly, and reversibly, increased with increasing bile salts concentration and reached a plateau at $40-50 \%$ in the absence of colipase and $80 \%$ in the presence of the latter. The effects of the colipase/lipase molar ratio were investigated by recording the EPR spectra of the spinlabeled HPL variant in a solution containing $4 \mathrm{mM}$ of NaTDC with variable amounts of colipase. Without colipase, the proportion of the slow-motion component spectrum was found to be $45 \%$, and this proportion was shown to gradually increase with increasing amounts of colipase and to reach a maximum of $70-75 \%$ above a two-fold molar excess.

In conclusion, these studies established a clear correlation between an EPR spectral shape and a conformational state of HPL and thus allowed a quantitative estimation of the opening of the lid under various conditions. In particular, the opening of the lid was observed in solution at room temperature in the presence of increasing bile salts concentrations. The opening of the lid was found to be already largely induced by bile salts before they reach the $\mathrm{CMC}$ (Figure 5 ), indicating that bile salts monomers are sufficient to stabilize the open conformation of HPL. This conclusion is supported by the analysis of the crystal structure of the open HPL showing detergent monomers ( $\beta$-octyl glucoside) interacting with the hydrophobic side of the lid [53]. Notably, the opening of the lid was shown to be a reversible process, as decreasing the bile salts concentration restored the EPR fast motion spectrum. In addition, and contrary to one previous report in the literature [43], colipase was found to be not strictly required to induce the opening of the lid, although it was found to stabilize the open conformation induced by bile salts. In a subsequent study [52], decreasing the $\mathrm{pH}$ was found to have the same effect as bile salts on the lid opening until a pH of 3. Below this threshold, the protein was found to be unfolded, as judged by both FTIR and EPR spectroscopy.

Finally, in a recent study, a strategy of double spin labeling was applied for measuring the amplitude of the lid opening via interspin distance measurements [54]. One spin label was introduced at the above-described position 249 of the mobile lid, while the second one was grafted at a rigid position (residue 181) of $\mathrm{HPL}$, where an accessible cysteine residue naturally occurs.

Using pulsed EPR and the bi-labeled HPL sample frozen at $70 \pm 5 K$, DEER experiments were carried out. From these studies, the inter-spin label distance of the closed conformation of HPL was estimated to be $19 \pm 2 \AA$ (Figure 6A). A magnetic interaction was however detected by continuous wave EPR experiments at room temperature (296K), suggesting that a fraction of bi-labeled HPL contained spin labels separated by a shorter distance. These results could be accounted for by the presence of two conformational sub-ensembles for the spin label side chain at position 249 when the lid was closed. The existence of these conformational subensembles was revealed by the simulation of the EPR spectra and was confirmed by molecular dynamics simulations. When the lid opening was induced by the addition of bile salts and colipase, a larger distance ( $42 \pm 2 \AA$ ) between the two spin labels was estimated from the DEER experiments (Figure 6A). The distances measured between the spin labels grafted at positions 181 and 249 were found to be in good agreement with those estimated from the known X-ray structures of HPL in the closed and open conformations (Figure 6B). Notably, these experiments allowed 

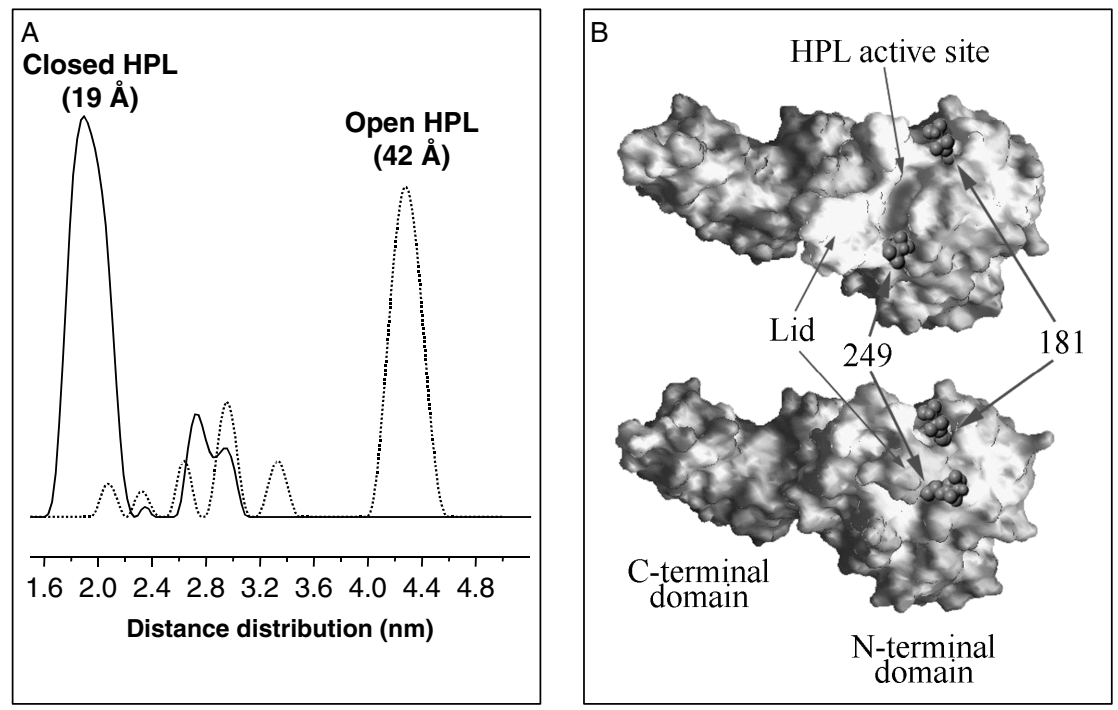

Figure 6. (A) Inter-spin label distance distributions of bi-labeled HPL either alone (solid line) or in the presence of bile salts and colipase (dotted line) obtained by DEER experiments and processed by Tikhonov regularization methods using the DeerAnalysis software [55]. When bi-labeled HPL was alone in solution, a single distance distribution of $19 \pm 2 \AA$ was found. In the presence of bile salts and colipase (i.e. under conditions known to induce the opening of the lid), the inter-spin distance distribution is shifted to $42 \pm 2 \AA$, indicating that residue 249 is pushed away from residue 181 . The minor peaks between 25 and $35 \AA$ are either artifacts generated by the mathematical processing of data, or may correspond to minor intermediate conformations of the HPL lid. (B) Molecular surface representation of HPL in its open (top) and closed (bottom) conformations (pdb codes 1LPA and 1N8S, respectively). Hydrophobic and polar surfaces are shown in white and gray, respectively. Residues 249 and 181 targeted for spin labeling are shown in the space-filling model. The picture was drawn using PyMOL (DeLano Scientific, San Carlos, CA; http://www.pymol.org) [51].

for the first time measuring the amplitude of the lid opening in solution or in a frozen solution in the presence of amphiphiles.

\section{Application of SDSL EPR Spectroscopy to the Study of the Induced Folding of the Intrinsically Disordered $\mathrm{N}_{\text {TAIL }}$ Domain of the Measles Virus Nucleoprotein}

As SDSL EPR spectroscopy has been extensively used to study folding and unfolding processes of structured proteins in the presence of denaturing agents [56-60], it was also expected to be well suited to assess induced folding events, i.e. disorderto-order transitions experienced by IDPs upon binding to their physiological partners.

IDPs are ubiquitous proteins that fulfill essential biological functions while being devoid of highly populated secondary and tertiary structure under physiological conditions and in the absence of a partner and rather exist as dynamic ensembles of inter-converting conformers [61-66]. Although there are IDPs that carry out their function while remaining permanently disordered (e.g. entropic chains) [66], many of them undergo induced folding $[62,67]$. Because of their inherent flexibility, IDPs escape atomistic description using X-ray crystallography: due to the considerable flexibility of the chain, IDPs generally fail to be crystallized and crystals can only be obtained for IDPs bound to a partner, provided that the disorder-to-order transition warrants a sufficient gain of rigidity compatible with the crystal nucleation process. By contrast, spectroscopic approaches, including SDSL EPR spectroscopy, are ideally well suited to study IDPs and to monitor the structural transitions they undergo in the presence of ligands/partners.

We therefore applied this technique to investigate the induced folding of the intrinsically disordered C-terminal domain of MeV $\mathrm{N}$, in the presence of the C-terminal X domain (XD, aa 459-507) of $\mathrm{P}$. MeV $\mathrm{N}$ consists of two regions: a structured $\mathrm{N}$-terminal moiety and a C-terminal domain, $\mathrm{N}_{\text {TAIL }}$ (aa 401-525), that is intrinsically unstructured [68] and exposed at the surface of the viral nucleocapsid [69]. NTAIL recruits the polymerase complex, made of the large protein $(L)$ and of $P$, via an interaction with $X D$. Binding to XD triggers the $\alpha$-helical folding of $\mathrm{N}_{\text {TAIL }}$ [70]. Within a conserved region of $\mathrm{N}_{\text {TAlL }}$ (aa 489-506, Box 2), an $\alpha$-helical molecular recognition element ( $\alpha$-MoRE) involved in binding to $P$ and in induced folding was identified [71] and modeled in the crystal structure of XD [70]. This model has been successively validated by Kingston and co-workers who solved the crystal structure of a chimeric construct consisting of XD and of the 486-504 region of $\mathrm{N}_{\text {TAIL }}$ [72]. Using SAXS, a low-resolution structural model of the complex between XD and the entire $N_{\text {TAIL }}$ domain has been obtained [73] (Figure 7A). This model showed that most of $\mathrm{N}_{\text {TAlL }}$ (residues $401-488$ ) remains disordered in the complex and does not establish contacts with XD. It also provides evidence for the involvement of the $\mathrm{N}_{\text {TAIL }}$ region downstream the $\alpha$-MoRE in binding to XD. That $\mathrm{N}_{\text {TAlL }}$ possesses an additional site (Box3, aa 517-525) involved in the interaction with XD has been further confirmed by several approaches, including surface plasmon resonance, CD and both fluorescence and NMR spectroscopy [73].

Although the $\mathrm{N}_{\text {TAlL }}-\mathrm{XD}$ interaction has been the focus of numerous studies (for reviews see [74-78]), only partial structural information on the $\mathrm{N}_{\text {TAIL }}-\mathrm{XD}$ complex was available by the time we undertook the characterization of both the free and bound form of $\mathrm{N}_{\text {TAIL }}$ by SDSL EPR spectroscopy. Indeed, SAXS data only provided low-resolution structural information, and crystallographic data were only available for a chimeric construct containing only 18 out of $125 \mathrm{~N}_{\text {TAlL }}$ residues [72], while the full assignment of the HSQC spectrum of $\mathrm{N}_{\text {TAlL }}$ in both the free and bound form has become available only recently [79]. In addition, the exact contribution of Box3 to binding to XD was unclear.

In order to more precisely map the $\alpha$-helical folding that $\mathrm{N}_{\text {TAIL }}$ undergoes in the presence of XD, and to achieve a better understanding of the molecular mechanisms governing this 

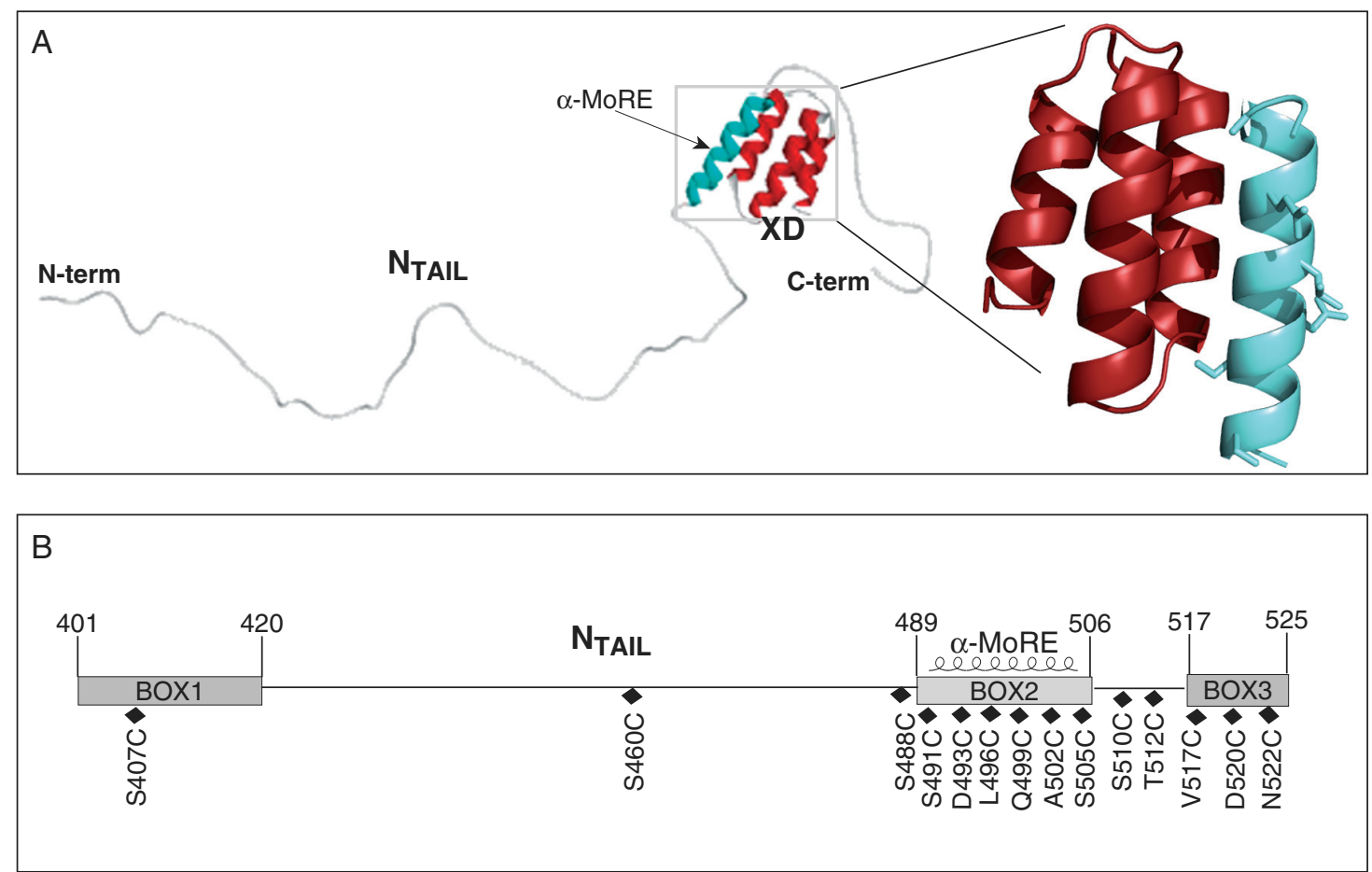

Figure 7. (A) Model of the $\mathrm{N}_{\text {TAlL }}$-XD complex as derived by small-angle X-ray scattering studies, highlighting the involvement of the $\alpha$-MoRE and of the $C$-terminus of $\mathrm{N}_{\text {TAIL }}$ in the interaction with XD [73]. The structure of the chimera between XD and the $\mathrm{N}_{\text {TAlL }}$ region encompassing residues 486 -504 (PDB code: 1T60) is zoomed in, and the side chains of residues targeted for cysteine substitution and spin labeling are shown. The picture was drawn using PyMOL (DeLano Scientific, San Carlos, CA; http://www.pymol.org) [51]. (B) Schematic representation of positions targeted for cysteine substitution and spin labeling (diamonds). The three regions of homology conserved in Morbillivirus members (Box1, Box2, and Box3) are also shown.

folding process, we targeted for spin-labeling 14 sites within $\mathrm{N}_{\text {TAlL}}, 12$ of which are scattered in the $488-525$ region, while two (positions 407 and 460) are located outside the reported region of interaction with XD (Figure 7B) [80]. Fourteen single-site cysteine variants were designed and purified from the soluble fraction of Escherichia coli. Spin labeling of all $N_{\text {TAIL variants was }}$ carried out using the same labeling procedure used during the mono spin-labeling of HPL [46]. Labeling yields ranged from 50 to $80 \%$. Differences in labeling yields were not position-dependent and were ascribed to more subtle differences in the experimental conditions rather than to a different extent of solvent-exposure of the sulfydryl group, in agreement with the prevalently unfolded state of $\mathrm{N}_{\text {TAIL }}$ [80].

The possibility that the cysteine substitution and the introduction of the spin label might affect the overall structure and the folding propensities of the $\mathrm{N}_{\text {TAlL }}$ variants was checked and ruled out by far-UV CD [80].

The EPR spectra of all $\mathrm{N}_{\text {TAlL }}$ variants were recorded at room temperature. For all the spin-labeled $\mathrm{N}_{\text {TAlL }}$ proteins, the EPR spectra are indicative of a high radical mobility, as judged on the basis of the ratio of the peak-to-peak amplitudes of the low field and central field lines $(h(+1) / h(0)$ ratio) that is a sensitive indicator of the radical mobility in the fast motional regime and that decreases with decreasing radical mobilities [31,80] (Figure 8, left panel). The EPR spectra exhibit a relatively narrow, single-component shape, with an outer line splitting of $3.22 \pm 0.02 \mathrm{mT}$ (Figure 8, left panel). Despite the overall high mobility, slight differences were observed in the different spin-labeled $\mathrm{N}_{\text {TAlL }}$ proteins. These differences in mobility could reflect differences in the content of transient secondary structure elements in the local environment experienced by each label.
EPR spectra were also recorded in the presence of either the secondary structure stabilizer TFE or the physiological partner XD (both either in the absence or in the presence of 30\% sucrose) (Figure 8, right panel and data not shown). In all cases, addition of stoichiometric amounts of XD was not sufficient to lead to saturation, with a two-fold molar excess of XD being required in most cases. For each EPR spectrum (except for the S491C NTAIL variant in the presence of XD), we measured the $h(+1) / h(0)[31,80]$. The effects of XD on the mobility of the spin label ranged from null (positions 407 and 460) to either dramatic (positions 488-502) or significant though less pronounced (positions 505-522). For position 491, which is the only one whose side chain is located at the XD-binding interface (Figure 9A), the mobility of the spin label was so dramatically reduced that the $h(+1) / h(0)$ parameter was no longer appropriate. In the case of the S491C $\mathrm{N}_{\text {TAlL }}$ variant (Figure 9A), the experimentally observed EPR spectrum consists of two components: one arising from the unbound spin-labeled protein and one resulting from the spin-labeled protein bound to XD (Figure 9B,C). The one-component spectrum corresponding to the bound form of the labeled protein was obtained upon subtracting the spectrum of free spin-labeled protein from the composite spectrum. The percentages of free and bound forms were calculated from the ratio of the integrated intensities, as already described above for HPL. They were estimated to be $25 \pm 5 \%$ and $75 \pm 5 \%$, respectively. The inability of spin-labeled S491C to bind to XD at $100 \%$ under saturating conditions, was ascribed to the occurrence of two protein populations in solution, one of which (25\%) would be unable to bind to XD even at over-saturating XD concentrations. These two populations were proposed to reflect static disorder, i.e. two alternate conformations of the side chain in position 491 (and hence of the spin label) with 

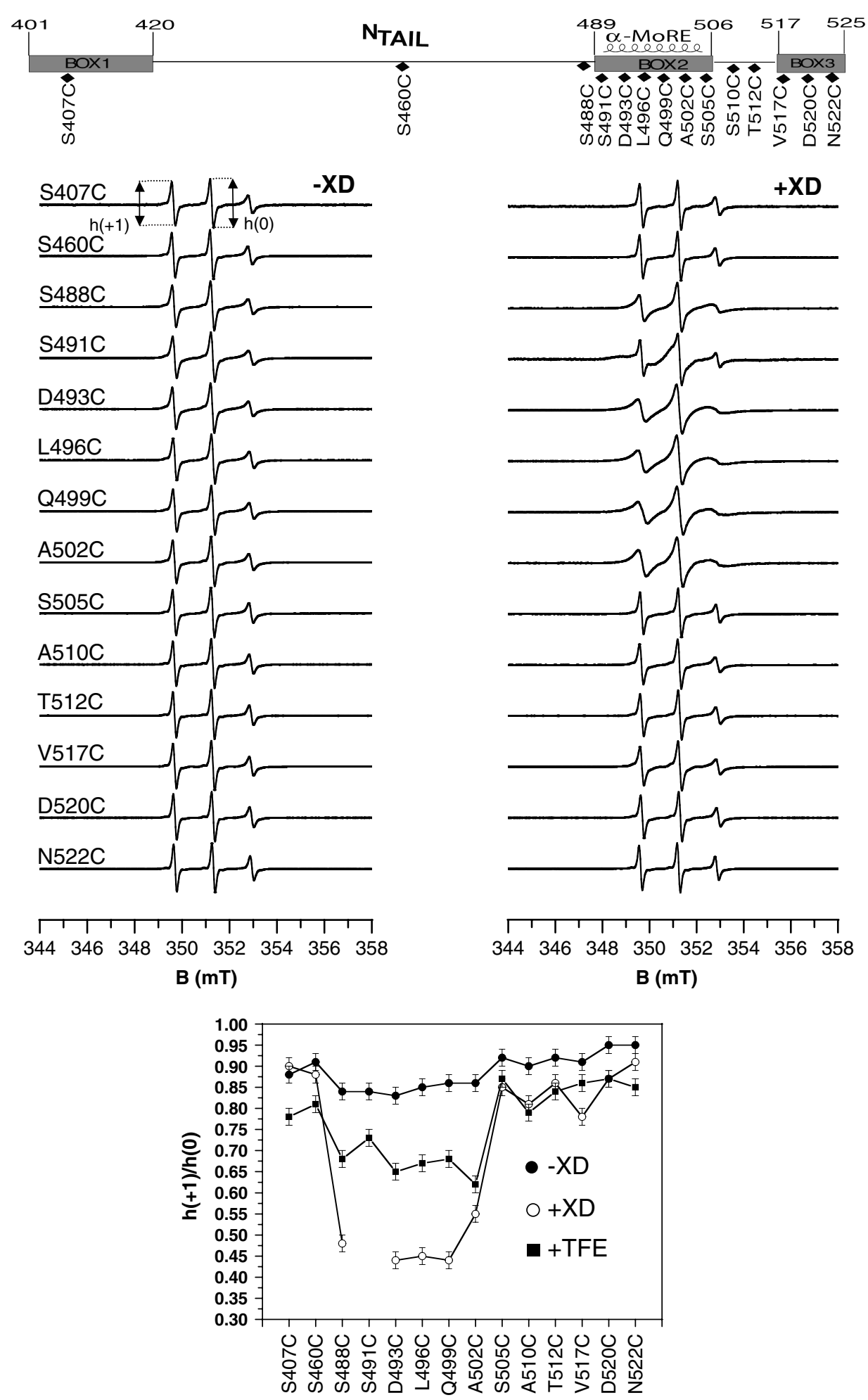

Figure 8. Normalized room temperature EPR spectra of the spin-labeled $\mathrm{N}_{\text {TAlL }}$ proteins $(100 \mu \mathrm{M})$ in the absence (left panel) or presence of a molar excess of XD (right panel). The spectra were recorded on an ESP 300E Bruker spectrometer equipped with an ELEXSYS Super High Sensitivity resonator operating at $9.9 \mathrm{GHz}$. The microwave power was $10 \mathrm{~mW}$ and the magnetic field modulation frequency and amplitude were $100 \mathrm{kHz}$ and $0.1 \mathrm{mT}$, respectively. The bottom panel shows the $h(+1) / h(0)$ ratios of the spin-labeled $N_{\text {TAll }}$ proteins free and in the presence of either saturating amounts of XD or $20 \%$ TFE as a function of spin-label position. Note that the $h(+1) / h(0)$ ratio of the spin-labeled S491C variant was not indicated, as it is not a reliable indicator of the mobility of this spin label (see text). The schematic representation of the $\mathrm{N}_{\text {TAlL }}$ variants is shown on the top. Data were taken from $[31,80]$. 

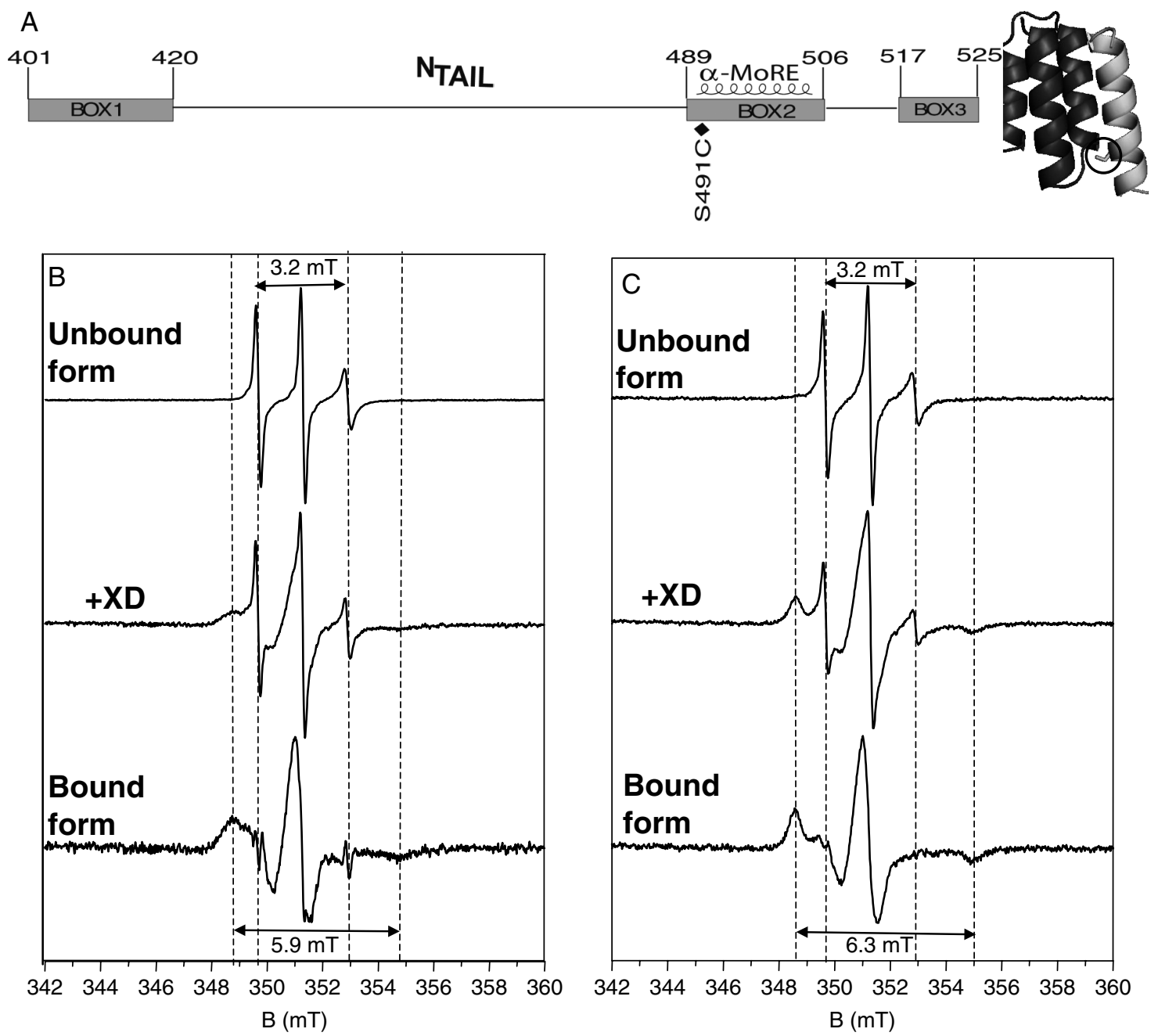

Figure 9. (A) Schematic representation of the $S 491 \mathrm{C} \mathrm{N}_{\text {TAlL }}$ variant and structure of the chimera between $\mathrm{XD}$ and the $\mathrm{N}_{\text {TAlL }}$ region encompassing residues 486-504 (PDB code: 1T60), where the side chain of residue S491 is shown. The picture was drawn using PyMOL (DeLano Scientific, San Carlos, CA; http://www.pymol.org) [51]. (B) and (C) Normalized room temperature EPR spectra of the spin-labeled S491C NTAll protein (100 $\mu$ M) in the absence (B) or presence (C) of 30\% sucrose either in the absence (top) or in the presence of saturating amounts of XD (middle). The EPR spectra were recorded using the same settings described for Figure 8. The EPR spectra shown at the bottom were obtained upon subtraction of the spectra of the unbound form (top) from the composite spectra (middle). The horizontal arrows indicate the outer line splitting for the free and bound forms.

an occupancy of 0.75 and of 0.25 . In the less populated one, the spin label would occur in a spatial position that would cause steric hindrance thereby preventing formation of a complex with XD. Indeed, the side chain of the native serine residue at position 491 is buried at the interface in the complex with XD (pdb code $1 \mathrm{T60}$ ) (Figure 9A). The finding that the grafting of the radical at the binding interface does not abolish complex formation and yet results in a highly constrained motion of the spin label is in agreement with earlier observations showing that nitroxide spin labels are tolerated at contact surfaces [82-85]. Interestingly however, in the case of the $\mathrm{N}_{\text {TAIL }}$-XD complex, although the grafting of the nitroxide radical at this position does not suppress complex formation, it causes a significant reduction in affinity and impairs the ability of the protein to yield $100 \%$ complex formation.

The occurrence of a considerable conformational heterogeneity at position 491 has been further confirmed in a subsequent EPR study [86], as well as in a vibrational spectroscopy study of cyanylated single cysteine variants of $\mathrm{N}_{\text {TAIL }}$ [87].

In agreement with the location of the radical buried at the $\mathrm{N}_{\text {TAIL }}$ /XD interface (Figure 9A), the EPR spectrum obtained in the presence of saturating amounts of XD is typical of a highly restricted mobility of the spin label, as judged by the appearance of a novel spectral lineshape with a broader outer line splitting $(5.95 \pm 0.05$ $\mathrm{mT}$ ) as compared to the unbound form (3.22 $\pm 0.02 \mathrm{mT}$ ) (Figure 9B). As expected, this effect is even more pronounced in the presence of $30 \%$ sucrose (Figure $9 \mathrm{C}$ ), where the mobility of the radical is severely restricted and approaches the so-called 'rigid-limit' regime obtained for a frozen solution of the free radical.

EPR experiments in the presence of $30 \%$ sucrose (a condition where the contribution of protein rotation to the EPR spectral line shape is reduced) allowed us to precisely map to residues $488-502$, the $\mathrm{N}_{\text {TAlL }}$ region undergoing $\alpha$-helical folding [80]. Indeed, under these conditions, the obtained spectra were found to be reminiscent of those observed with spin-labeled variants of proteins in which the radicals have been grafted at the surface of helices [32].

In order to assess whether the restrained motion of the 505-522 region observed upon addition of XD was due to a gain of rigidity arising from $\alpha$-helical folding of the neighboring Box 2 region or to the presence of $\mathrm{XD}$, which might restrain the conformational 
space available to the radicals grafted within the $C$-terminal region of $\mathrm{N}_{\text {TAIL, }}$, we monitored the gain of rigidity that $\mathrm{N}_{\text {TAIL }}$ undergoes in the presence of $20 \%$ TFE, a condition where the impact of the $\alpha$-helical folding of Box 2 upon the mobility of the radicals grafted downstream can be assessed and separated from the effect due to complex formation with XD. Addition of $20 \%$ TFE was shown to trigger a decrease in the mobility of the spin labels bound within the 505-522 region that is comparable to that induced by XD (Figure 8). Taking also into account the fact that TFE was known not to promote $\alpha$-helical folding within Box3 [73], these data suggest that the $\alpha$-helical transition taking place within Box2 is responsible for the restrained motion of the downstream region, rather than a direct interaction with $\mathrm{XD}$. On the other hand, the reduction in the mobility of the spin labels grafted in the 488-502 region is more pronounced in the presence of XD than in the presence of $20 \%$ TFE (Figure 8 ), suggesting that XD would stabilize the formation of the $\alpha$-MoRE, which would be only transiently populated in the unbound form of $\mathrm{N}_{\text {TAIL }}$ in the presence of TFE. Notably, lack of stable contacts between Box3 and XD, was also confirmed by heteronuclear NMR titration experiments using ${ }^{15} \mathrm{~N}$-labeled XD with an unlabeled Box3 peptide (aa 505-525) [88], although similar studies with ${ }^{15} \mathrm{~N}$-labeled $\mathrm{N}_{\text {TAlL }}$ did show a magnetic perturbation of the Box3 region upon addition of XD [79]. To date, the precise mechanism by which Box3 contributes to binding remains poorly understood.

On a more methodological side, the higher impact of TFE on the mobility of the radicals grafted within the $488-502$ region as compared to that of radicals grafted to other $\mathrm{N}_{\text {TAIL }}$ positions points out the relevance of studies making use of TFE. Indeed, while the reliability of structural information derived by $C D$ studies in the presence of TFE is still a matter of debate, with artifactual (i.e. non-native) $\alpha$-helical folding induced by this solvent being often evoked [89-91], these results clearly indicate that the extent of TFE impact on radical mobility well reflects the inherent structural propensities of the various protein regions, with the 505-522 region, as well as positions 407 and 460, being 'resistant' to undergoing $\alpha$-helical folding. Altogether, these data show that, in the case of $\mathrm{N}_{\text {TAIL, }}$ TFE does not promote non-native folding, thus pointing out the relevance of studies making use of TFE to infer information about protein structural propensities.

Altogether, these experiments showed that different $\mathrm{N}_{\text {TAIL }}$ regions contribute to a different extent to the binding to XD. Indeed, while the mobility of the spin labels grafted at positions 407 and 460 is unaffected upon addition of XD, that of the spin labels grafted within the 488-502 and the 505-522 regions is severely and moderately reduced, respectively, with position 491 experiencing a very restrained mobility and with $\alpha$-helical folding only concerning the 488-502 region (Figures 8 and 9). Notably, the mobility of this latter region was found to be restrained even in the absence of the partner (Figure 8), a behavior that could be accounted for by the existence of a transiently populated folded state. The occurrence of a transiently populated $\alpha$-helix even in the absence of the partner suggests that the molecular mechanism governing the folding of $\mathrm{N}_{\text {TAIL }}$ induced by XD could rely, at least partly, on conformer selection (i.e. selection by the partner of a pre-existing conformation) [92,93] rather than on a 'fly casting' mechanism [94].

Furthermore, in equilibrium displacement experiments, we showed that the XD-induced folding of $\mathrm{N}_{\text {TAIL }}$ is a reversible process, with $\mathrm{N}_{\text {TAlL }}$ adopting its original prevalently unfolded conformation upon dissociation of XD from the complex [80].

Finally, in a recent study, a novel approach to describe the structure of partly disordered protein complexes has been

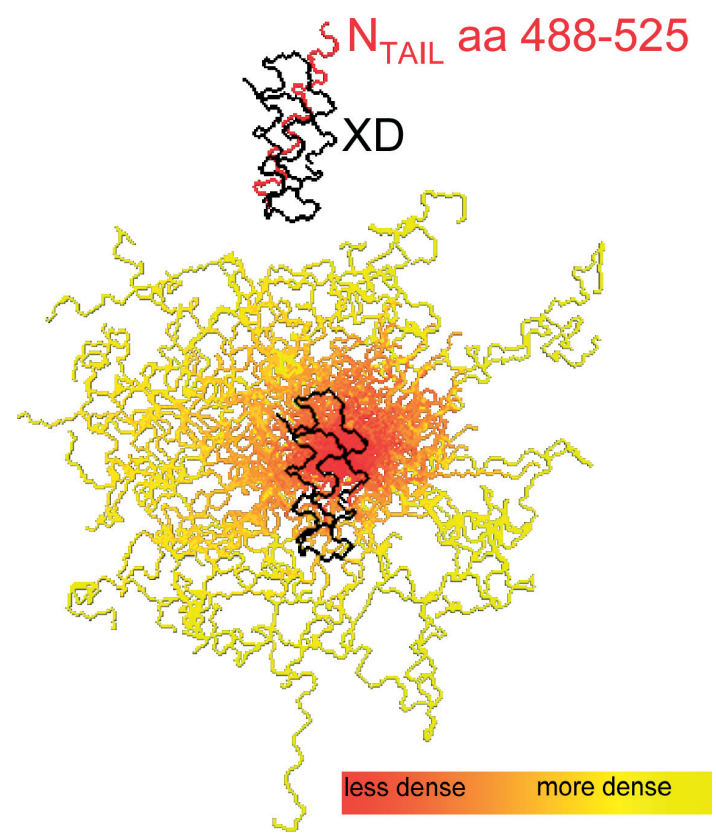

Figure 10. Model of the partly disordered $\mathrm{N}_{\text {TAIL }} \mathrm{XD}$ complex as a conformational ensemble. Fifty best-fit structures of the 488-525 region of $\mathrm{N}_{\text {TAIL }}$ in complex with XD. The $\mathrm{N}_{\text {TAIL }}$ conformers are depicted with a color gradient ranging from yellow to red with decreasing structural density, while XD is shown in black.

proposed and applied to the intrinsically disordered $\mathrm{N}_{\text {TAlL }}$ domain both free and in complex with XD (Figure 10) [86]. This original approach relies on a combination of SDSL EPR spectroscopy and modeling of local rotation conformational spaces. By comparing measured and modeled temperature-dependent restrictions of side-chain conformational spaces of 12 out of the 14 abovedescribed spin-labeled $\mathrm{N}_{\text {TAIL }}$ variants, the $490-500$ region of $\mathrm{N}_{\text {TAIL }}$ was shown to be effectively pre-structured in the absence of the partner and the extent of the $\alpha$-helical sampling of the free form could be quantitatively estimated. In addition, the 505-525 region of $\mathrm{N}_{\text {TAlL }}$ was found to conserve a significant degree of freedom even in the bound form [86], in agreement with previous spectroscopic studies [88].

As a last note, the large number of spin-labeled $\mathrm{N}_{\text {TAIL }}$ variants that were generated, together with their analysis by EPR spectroscopy, provides a panel of spectral signatures that have a high predictive value. Indeed, since the EPR spectral shape reflects the specific environment in the proximity of the spin label, together with the extent of involvement of the radical in the interaction with a partner and in possible $\alpha$-helical transitions, one should be able to infer information on the chemical environment and the implication of specific $\mathrm{N}_{\text {TAIL }}$ residues within complexes with other partners, such as the $\mathrm{N}_{\text {TAIL }}-\mathrm{Hsp} 72$ complex $[95,96]$ for which no structural information are presently available.

\section{Conclusions and Perspectives}

Monitoring conformational changes in proteins is of a broad general interest because structural transitions are involved in many biochemical processes, including allosteric enzymatic activity regulation, molecular recognition and assembly, signal transduction, cell cycle regulation, transcription, and amyloidogenesis associated to neurodegenerative diseases. 
SDSL EPR spectroscopy has been shown to be a valuable approach to document structural transitions in proteins. Even when high-resolution structural data are available, SDSL EPR spectroscopy can provide invaluable information: indeed, while X-ray crystallography mainly provides static pictures corresponding to snapshots of extreme conformational stages, SDSL EPR spectroscopy allows monitoring structural transitions in solution under conditions close to the physiological ones, and also yields quantitative information about the parameters inducing conformational changes and the relative proportions of structural intermediates. In addition, SDSL EPR spectroscopy has been proven to be a powerful method for studying induced folding events within IDPs: not only it provides information at the residue level, but also allows atomistic description of partly disordered complexes as conformational ensembles. As such, it can be added to the panel of widely used experimental approaches $[97,98]$ to study induced folding events.

In spite of its proven suitability for studying structural transitions in proteins, SDSL approaches are limited by the fact that only a limited number of nitroxide radicals are commercially available, with all of these targeting cysteine residues. The fact that cysteine residues are often crucial for the biological function represents a serious limitation of this technique. Recent developments based on the use of unnatural amino acids and of orthogonal labeling strategies represent valuable alternative approaches to circumvent these limitations $[99,100]$. The incorporation of such unnatural amino acids relies, however, on a rather complex strategy where an orthogonal tRNA/aminoacyl-tRNA synthetase pair specific for the unnatural amino acid added to the media is co-expressed together with the gene of interest bearing a TAG amber codon at the desired incorporation site $[99,100]$. Future developments of SDSL EPR spectroscopy will certainly benefit from the design and synthesis of new paramagnetic labels allowing grafting on sites other than cysteine and/or yielding different spectroscopic signatures. These methodological improvements are the focus of our current efforts.

\section{Acknowledgements}

The works herein described were carried out with the financial support of the Agence Nationale de la Recherche, specific programs 'Microbiologie et Immunologie' (ANR-05-MIIM-035) and 'Program Blanc' (ANR-09-BLAN-0100), of the National Institute of Neurological Disorders and Stroke (R01 NS031693-11A2), of the CNRS, and of the COST P15 action. We wish to thank our collaborators who contributed to the herein described studies. In particular, we would like to thank Benjamin Morin, Jean-Marie Bourhis, Sabrina Rouger, Elodie Liquière, Guillaume Setrick, and Stéphanie Costanzo from the AFMB lab for $\mathrm{N}_{\text {TAIL }}$ variant production and spin labeling, Sébastien Ranaldi and Mireille Woudstra from the BIP laboratory for lipase production and EPR studies, Hervé Vezin from the laboratory of Chimie Organique et Macromoléculaire (CNRS UMR 8009) for the DEER experiments, Philippe Roche from the laboratory Interactions et Modulateurs de Réponses (CNRS UPR 3243) for molecular dynamics studies, James Sturgis from the Laboratory of Ingénierie des Systèmes Macromoléculaires (CNRS UPR 9027) for the FTIR studies of HPL, Virginie Thomé, Julie Currault, Jorge Rodriguez, and Robert Verger from the EIPL lab for lipase variant production and for fruitful discussions, and Janez Strancar from the Laboratory of
Biophysics, 'Josef Stefan' Institute, Ljubljana (Slovenia) for the modeling of the partly disordered $\mathrm{N}_{\text {TAIL }}$ XD complex based on EPR data.

\section{References}

1 Feix JB, Klug CS. Site-directed spin-labeling of membrane proteins and peptide-membrane interactions. In Biological Magnetic Resonance. Berliner L (ed). Plenum Press: New York, 1998; 251-281.

2 Hubbell WL, McHaourab HS, Altenbach C, Lietzow MA. Watching proteins move using site-directed spin labeling. Structure 1996; 4: 779-783.

3 Hubbell WL, Gross A, Langen R, Lietzow MA. Recent advances in site-directed spin labeling of proteins. Curr. Opin. Struct. Biol. 1998; 8: 649-656.

4 Hubbell WL, Cafiso DS, Altenbach C. Identifying conformational changes with site-directed spin labeling. Nat. Struct. Biol. 2000; 7: 735-739.

5 Biswas R, Kuhne H, Brudvig GW, Gopalan V. Use of EPR spectroscopy to study macromolecular structure and function. Sci. Prog. 2001; 84: 45-67.

6 Hubbell WL, Altenbach C, Hubbell CM, Khorana HG. Rhodopsin structure, dynamics, and activation: a perspective from crystallography, site-directed spin labeling, sulfhydryl reactivity, and disulfide cross-linking. Adv. Protein Chem. 2003; 63: 243-290.

7 Fanucci GE, Cafiso DS. Recent advances and applications of sitedirected spin labeling. Curr. Opin. Struct. Biol. 2006; 16: 644-653.

8 Klare JP, Steinhoff HJ. Spin labeling EPR. Photosynth. Res. 2009; 102: 377-390.

9 Altenbach C, Flitsch SL, Khorana HG, Hubbell WL. Structural studies on transmembrane proteins. 2. Spin labeling of bacteriorhodopsin mutants at unique cysteines. Biochemistry 1989; 28: 7806-7812.

10 Altenbach C, Marti T, Khorana HG, Hubbell WL. Transmembrane protein-structure: spin labeling of bacteriorhodopsin mutants. Science 1990; 248: 1088-1092.

11 Steinhoff HJ, Mollaaghababa R, Altenbach C, Hideg K, Krebs M, Khorana HG, Hubbell WL. Time-resolved detection of structural changes during the photocycle of spin-labeled bacteriorhodopsin. Science 1994; 266: 105-107.

12 Thorgeirsson TE, Xiao WZ, Brown LS, Needleman R, Lanyi JK, Shin YK. Transient channel-opening in bacteriorhodopsin: an EPR study. J. Mol. Biol. 1997; 273: $951-957$.

13 Klug CS, Eaton SS, Eaton GR, Feix JB. Ligand-induced conformational change in the ferric enterobactin receptor FepA as studied by site-directed spin labeling and time-domain ESR. Biochemistry 1998; 37: 9016-9023.

14 Perozo E, Cortes DM, Cuello LG. Structural rearrangements underlying $\mathrm{K}+-$-channel activation gating. Science 1999; 285: 73-78.

15 Ottemann KM, Xiao WZ, Shin YK, Koshland DE. A piston model for transmembrane signaling of the aspartate receptor. Science 1999; 285: $1751-1754$.

16 Fanucci GE, Coggshall KA, Cadieux N, Kim M, Kadner RJ, Cafiso DS. Substrate-induced conformational changes of the perplasmic $\mathrm{N}$ terminus of an outer-membrane transporter by site-directed spin labeling. Biochemistry 2003; 42: 1391 - 1400.

17 Schweiger A, Jeschke G. Principles of Pulse Electron Resonance. Oxford University Press: New York, 2005.

18 Pannier M, Veit S, Godt A, Jeschke G, Spiess HW. Dead-time free measurement of dipole-dipole interactions between electron spins. J. Magn. Reson. 2000; 142: $331-340$.

19 Jeschke G. Distance measurements in the nanometer range by pulse EPR. ChemPhysChem 2002; 3: 927-932.

20 Jeschke G, Panek G, Godt A, Bender A, Paulsen H. Data analysis procedures for pulse ELDOR measurements of broad distance distributions. Appl. Magn. Reson. 2004; 26: 223-244.

21 Jeschke G, Bender A, Schweikardt T, Panek G, Decker H, Paulsen H. Localization of the $\mathrm{N}$-terminal domain in light-harvesting chlorophyll a/b protein by EPR measurements. J. Biol. Chem. 2005; 280: $18623-18630$.

22 Altenbach C, Kusnetzow AK, Ernst OP, Hofmann KP, Hubbell WL. High-resolution distance mapping in rhodopsin reveals the pattern of helix movement due to activation. Proc. Natl. Acad. Sci. U. S. A. 2008; 105: 7439-7444. 
23 Drescher M, Veldhuis G, van Rooijen BD, Milikisyants S, Subramaniam V, Huber M. Antiparallel arrangement of the helices of vesicle-bound alpha-synuclein. J. Am. Chem. Soc. 2008; 130: 7796-7797.

24 Galiano L, Ding F, Veloro AM, Blackburn ME, Simmerling C, Fanucci GE. Drug pressure selected mutations in HIV-1 protease alter flap conformations. J. Am. Chem. Soc. 2009; 131:430-431.

25 Jao CC, Hegde BG, Chen J, Haworth IS, Langen R. Structure of membrane-bound alpha-synuclein from site-directed spin labeling and computational refinement. Proc. Natl. Acad. Sci. U. S. A. 2008; 105: $19666-19671$.

26 Sugata K, Song LK, Nakamura M, Ueki S, Fajer PG, Arata T. Nucleotide-induced flexibility change in neck linkers of dimeric kinesin as detected by distance measurements using spin-labeling EPR. J. Mol. Biol. 2009; 386: 626-636.

27 Stoll S, Schweiger A. EasySpin, a comprehensive software package for spectral simulation and analysis in EPR. J. Magn. Reson. 2006; 178: $42-55$.

28 Timofeev VP, Tsetlin Vl. Analaysis of mobility of protein side chains by spin-label technique. Biophys. Struct. Mech. 1983; 10: 93-108.

29 Freed JH. Theory of slow tumbling ESR spectra for nitroxides. In Spin Labeling: Theory and Applications. Berliner LJ (ed). Academic press: New York, 1976; 53-132.

30 Budil DE, Lee S, Saxena S, Freed JH. Non linear least-squares analysis of slow motion EPR spectra in one and two dimensions using a modified Levenberg-Marquardt algorithm. J. Magn. Reson. A 1996; 120: $155-189$

31 Morin B, Bourhis JM, Belle V, Woudstra M, Carrière F, Guigliarelli B, Fournel A, Longhi S. Assessing induced folding of an intrinsically disordered protein by site-directed spin-labeling EPR spectroscopy. J. Phys. Chem. B 2006; 110: 20596-20608.

32 McHaourab HS, Lietzow MA, Hideg K, Hubbell WL. Motion of spinlabeled side chains in T4 lysozyme. Correlation with protein structure and dynamics. Biochemistry 1996; 35: 7692-7704.

33 Columbus L, Kalai T, Jeko J, Hideg K, Hubbell WL. Molecular motion of spin labeled side chains in alpha-helices: analysis by variation of side chain structure. Biochemistry 2001; 40: 3828-3846.

34 Columbus L, Hubbell WL. A new spin on protein dynamics. Trends Biochem. Sci. 2002; 27: 288-295.

35 Winkler FK, d'Arcy A, Hunziker W. Structure of human pancreatic lipase. Nature 1990; 343: 771-774.

36 van Tilbeurgh $\mathrm{H}$, Sarda L, Verger R, Cambillau C. Structure of the pancreatic lipase-procolipase complex. Nature 1992; 359: $159-162$.

37 van Tilbeurgh $\mathrm{H}$, Egloff M-P, Martinez C, Rugani N, Verger R, Cambillau C. Interfacial activation of the lipase-procolipase complex by mixed micelles revealed by X-Ray crystallography. Nature 1993; 362: 814-820.

38 Chahinian H, Bezzine S, Ferrato F, Ivanova MG, Perez B, Lowe ME, Carriere $F$. The beta $5^{\prime}$ loop of the pancreatic lipase C2-like domain plays a critical role in the lipase-lipid interactions. Biochemistry 2002; 41: 13725-13735.

39 Bezzine S, Ferrato F, Ivanova MG, Lopez V, Verger R, Carriere F. Human pancreatic lipase: colipase dependence and interfacial binding of lid domain mutants. Biochemistry 1999; 38: 5499-5510.

40 Brzozowski AM, Savage H, Verma CS, Turkenburg JP, Lawson DM, Svendsen A, Patkar S. Structural origins of the interfacial activation in Thermomyces (Humicola) lanuginosa lipase. Biochemistry 2000; 39: $15071-15082$.

41 Rouard M, Sari H, Nurit S, Entressangles B, Desnuelle P. Inhibition of pancreatic lipase by mixed micelles of diethyl $p$-nitrophenyl phosphate and the bile salts. Biochim. Biophys. Acta 1978; 530: 227-235.

42 Lüthi-Peng $Q$, Winkler FK. Large spectral changes accompany the conformational transition of human pancreatic lipase induced by acylation with the inhibitor tetrahydrolipstatin. Eur. J. Biochem. 1992; 205: 383-390.

43 Hermoso J, Pignol D, Penel S, Roth M, Chapus C, FontecillaCamps JC. Neutron crystallographic evidence of lipase-colipase complex activation by a micelle. EMBO J. 1997; 16: 5531-5536.

44 Pignol D, Ayvazian L, Kerfelec B, Timmins P, Crenon I, Hermoso J, Fontecilla-Camps JC, Chapus C. Critical role of micelles in pancreatic lipase activation revealed by small angle neutron scattering. J. Biol. Chem. 2000; 275: 4220-4224.
45 Moreau H, Moulin A, Gargouri Y, Noël J-P, Verger R. Inactivation of gastric and pancreatic lipases by diethyl $p$-nitrophenyl phosphate. Biochemistry 1991; 30: 1037-1041.

46 Belle V, Fournel A, Woudstra M, Ranaldi S, Prieri F, Thome V, Currault J, Verger R, Guigliarelli B, Carriere F. Probing the opening of the pancreatic lipase lid using site-directed spin labeling and EPR spectroscopy. Biochemistry 2007; 46: 2205-2214.

47 Verger R, Sarda L, Desnuelle P. The sulfhydryl groups of pancreatic lipase. Biochim. Biophys. Acta 1970; 207: 377-379.

48 Cudrey C, van Tilbeurgh H, Gargouri Y, Verger R. Inactivation of pancreatic lipases by amphiphilic reagents 5-(Dodecyldithio)2-nitrobenzoic acid and tetrahydrolipstatin. Dependence upon partitioning between micellar and oil phases. Biochemistry 1993; 32: $13800-13808$

49 Hjorth A, Carrière F, Cudrey $C$, Wöldike $H$, Boel E, Lawson DM, Ferrato F, Cambillau C, Dodson GG, Thim L, Verger R. A structural domain (the lid) found in pancreatic lipases is absent in the guinea pig (phospho)lipase. Biochemistry 1993; 32: 4702-4707.

50 Carrière F, Thirstrup K, Hjorth S, Boel E. Cloning of the classical guinea pig pancreatic lipase and comparison with the lipase related protein 2. FEBS Lett. 1994; 338: 63-68.

51 DeLano WL. The PyMOL molecular graphics system. Proteins Struct. Funct. Bioinform. 2002; 30: 442-454.

52 Ranaldi S, Belle V, Woudstra M, Rodriguez J, Guigliarelli B, Sturgis J, Carriere F, Fournel A. Lid opening and unfolding in human pancreatic lipase at low $\mathrm{pH}$ revealed by site-directed spin labeling EPR and FTIR spectroscopy. Biochemistry 2009; 48: 630-638.

53 Egloff M-P, Marguet F, Buono G, Verger R, Cambillau C, van Tilbeurgh $H$. The $2.46 \AA$ resolution structure of the pancreatic lipase-colipase complex inhibited by a $\mathrm{C}_{11}$ alkyl phosphonate. Biochemistry 1995; 34: 2751-2762.

54 Ranaldi S, Belle V, Woudstra M, Bourgeas R, Guigliarelli B, Roche P, Vezin H, Carriere F, Fournel A. Amplitude of pancreatic lipase lid opening in solution and identification of spin label conformational subensembles by combining continuous wave and pulsed EPR spectroscopy and molecular dynamics. Biochemistry 2010; 49: 2140-2149.

55 Jeschke G, Chechik V, lonita P, Godt A, Zimmermann H, Banham J, Timmel CR, Hilger D, Jung H. DeerAnalysis2006 - a comprehensive software package for analyzing pulsed ELDOR data. Appl. Magn. Reson. 2006; 30: 473-498.

56 Klug CS, Su W, Liu J, Klebba PE, Feix JB. Denaturant unfolding of the ferric enterobactin receptor and ligand-induced stabilization studied by site-directed spin labeling. Biochemistry 1995; 34: $14230-14236$.

57 Hammarstrom P, Owenius R, Martensson LG, Carlsson U, Lindgren $\mathrm{M}$. High-resolution probing of local conformational changes in proteins by the use of multiple labeling: unfolding and selfassembly of human carbonic anhydrase II monitored by spin, fluorescent, and chemical reactivity probes. Biophys. J. 2001; 80: $2867-2685$.

58 Teilum K, Kragelund BB, Poulsen FM. Transient structure formation in unfolded acyl-coenzyme A-binding protein observed by sitedirected spin labelling. J. Mol. Biol. 2002; 324: 349-357.

59 Dockter C, Volkov A, Bauer C, Polyhach Y, Joly-Lopez Z, Jeschke G, Paulsen $\mathrm{H}$. Refolding of the integral membrane protein lightharvesting complex II monitored by pulse EPR. Proc. Natl. Acad. Sci. U. S. A. 2009; 106: 18485-18490.

60 Babavali M, Esmann M, Fedosova NU, Marsh D. Urea-induced unfolding of $\mathrm{Na}$,K-ATPase as evaluated by electron paramagnetic resonance spectroscopy. Biochemistry 2009; 48: 9022-9030.

61 Wright PE, Dyson HJ. Intrinsically unstructured proteins: reassessing the protein structure-function paradigm. J. Mol. Biol. 1999; 293: 321-331.

62 Dyson HJ, Wright PE. Intrinsically unstructured proteins and their functions. Nat. Rev. Mol. Cell Biol. 2005; 6: 197-208.

63 Uversky VN. Natively unfolded proteins: a point where biology waits for physics. Protein Sci. 2002; 11: 739-756.

64 Uversky VN, Gillespie JR, Fink AL. Why are "natively unfolded" proteins unstructured under physiologic conditions?.Proteins 2000; 41: 415-427.

65 Dunker AK, Brown CJ, Obradovic Z. Identification and functions of usefully disordered proteins. Adv. Protein Chem. 2002; 62: 25-49.

66 Dunker AK, Lawson JD, Brown CJ, Williams RM, Romero P, Oh JS, Oldfield CJ, Campen AM, Ratliff CM, Hipps KW, Ausio J, Nissen MS, 
Reeves R, Kang C, Kissinger CR, Bailey RW, Griswold MD, Chiu W, Garner EC, Obradovic Z. Intrinsically disordered protein. J. Mol. Graph. Model. 2001; 19: 26-59.

67 Wright PE, Dyson HJ. Linking folding and binding. Curr. Opin. Struct. Biol. 2009; 19: 31-38.

68 Longhi S, Receveur-Brechot V, Karlin D, Johansson K, Darbon H, Bhella $D$, Yeo R, Finet $S$, Canard B. The C-terminal domain of the measles virus nucleoprotein is intrinsically disordered and folds upon binding to the C-terminal moiety of the phosphoprotein. J. Biol. Chem. 2003; 278: 18638-18648.

69 Karlin D, Longhi S, Canard B. Substitution of two residues in the measles virus nucleoprotein results in an impaired self-association. Virology 2002; 302: 420-432.

70 Johansson K, Bourhis JM, Campanacci V, Cambillau C, Canard B, Longhi S. Crystal structure of the measles virus phosphoprotein domain responsible for the induced folding of the C-terminal domain of the nucleoprotein. J. Biol. Chem. 2003; 278: 44567-44573.

71 Bourhis J, Johansson K, Receveur-Bréchot V, Oldfield CJ, Dunker AK, Canard B, Longhi S. The C-terminal domain of measles virus nucleoprotein belongs to the classof intrinsically disordered proteins that fold upon binding to their pohysiological partner. Virus Res. 2004; 99: 157-167.

72 Kingston RL, Hamel DJ, Gay LS, Dahlquist FW, Matthews BW. Structural basis for the attachment of a paramyxoviral polymerase to its template. Proc. Natl. Acad. Sci. U. S. A. 2004; 101: 8301-8306.

73 Bourhis JM, Receveur-Bréchot V, Oglesbee M, Zhang X, Buccellato $\mathrm{M}$, Darbon $\mathrm{H}$, Canard B, Finet S, Longhi S. The intrinsically disordered C-terminal domain of the measles virus nucleoprotein interacts with the C-terminal domain of the phosphoprotein via two distinct sites and remains predominantly unfolded. Protein Sci. 2005; 14: 1975-1992.

74 Bourhis JM, Canard B, Longhi S. Désordre structural au sein du complexe réplicatif du virus de la rougeole: implications fonctionnelles. Virologie 2005; 9: 367-383.

75 Bourhis JM, Canard B, Longhi S. Structural disorder within the replicative complex of measles virus: functional implications. Virology 2006; 344: 94-110.

76 Bourhis JM, Longhi S. Measles virus nucleoprotein: structural organization and functional role of the intrinsically disordered C-terminal domain. In Measles Virus Nucleoprotein. Longhi S (ed). Nova Publishers Inc.: Hauppage, NY, 2007; 1-35.

77 Longhi S. Nucleocapsid structure and function. Curr. Top. Microbiol. Immunol. 2009; 329: 103-128.

78 Longhi S, Oglesbee M. Structural disorder within the measles virus nucleoprotein and phosphoprotein. Protein Pept. Lett. 2010; 17: 961-978.

79 Gely S, Lowry DF, Bernard C, Ringkjobing-Jensen M, Blackledge M, Costanzo S, Darbon H, Daughdrill GW, Longhi S. Solution structure of the C-terminal $X$ domain of the measles virus phosphoprotein and interaction with the intrinsically disordered C-terminal domain of the nucleoprotein. J. Mol. Recognit. 2010; 23: 435-447.

80 Belle V, Rouger S, Costanzo S, Liquiere E, Strancar J, Guigliarelli B, Fournel A, Longhi S. Mapping alpha-helical induced folding within the intrinsically disordered C-terminal domain of the measles virus nucleoprotein by site-directed spin-labeling EPR spectroscopy. Proteins Struct. Funct. Bioinform. 2008; 73: 973-988.

81 Belle V, Rouger S, Costanzo S, Longhi S, Fournel A. Site-directed spin labeling EPR spectroscopy. In Instrumental Analysis of Intrinsically Disordered Proteins: Assessing Structure and Conformation. Uversky VN, Longhi S (eds). John Wiley and Sons: Hoboken, New Jersey, 2010.

82 Crane JM, Mao C, Lilly AA, Smith VF, Suo Y, Hubbell WL, Randall LL. Mapping of the docking of SecA onto the chaperone SecB by site-directed spin labeling: insight into the mechanism of ligand transfer during protein export. J. Mol. Biol. 2005; 353: 295-307.

83 Hanson SM, Francis DJ, Vishnivetskiy SA, Kolobova EA, Hubbell WL, Klug CS, Gurevich VV. Differential interaction of spin-labeled arrestin with inactive and active phosphorhodopsin. Proc. Natl. Acad. Sci. U. S. A. 2006; 103: 4900-4905.

84 Medkova M, Preininger AM, Yu NJ, Hubbell WL, Hamm HE. Conformational changes in the amino-terminal helix of the $G$ protein alpha(i1) following dissociation from Gbetagamma subunit and activation. Biochemistry 2002; 41: 9962-9972.

85 Van Eps N, Oldham WM, Hamm HE, Hubbell WL. Structural and dynamical changes in an alpha-subunit of a heterotrimeric $G$ protein along the activation pathway. Proc. Natl. Acad. Sci. U. S. A. 2006; 103: 16194-16199.

86 Kavalenka A, Urbancic I, Belle V, Rouger S, Costanzo S, Kure S, Fournel A, Longhi S, Guigliarelli B, Strancar J. Conformational analysis of the partially disordered measles virus NTAIL-XD complex by SDSL EPR spectroscopy. Biophys J. 2010; 98: 1055-1064.

87 Bischak CG, Longhi S, Snead DM, Costanzo S, Terrer E, Londergan $\mathrm{CH}$. Probing structural transitions in the intrinsically disordered C-terminal domain of the measles virus nucleoprotein by vibrational spectroscopy of cyanylated cysteines. Biophys. J. 2010; 99: $1676-1683$.

88 Bernard C, Gely S, Bourhis JM, MorelliX, Longhi S, Darbon H. Interaction between the $\mathrm{C}$-terminal domains of $\mathrm{N}$ and $\mathrm{P}$ proteins of measles virus investigated by NMR. FEBS Lett. 2009; 583: 1084-1089.

89 Luo P, Baldwin RL. Mechanism of helix induction by trifluoroethanol: a framework for extrapolating the helix-forming properties of peptides from trifluoroethanol/water mixtures back to water. Biochemistry 1997; 36: 8413-8421.

90 Buck M. Trifluoroethanol and colleagues: cosolvents come of age. Recent studies with peptides and proteins. Q. Rev. Biophys. 1998; 31: 297-355.

91 Fan P, Bracken C, Baum J. Structural characterization of monellin in the alcohol-denatured state by NMR: evidence for beta-sheet to alpha-helix conversion. Biochemistry 1993; 32: 1573-1582.

92 Tsai CD, Ma B, Kumar S, Wolfson H, Nussinov R. Protein folding: binding of conformationally fluctuating building blocks via population selection. Crit. Rev. Biochem.Mol.Biol. 2001;36:399-433.

93 Tsai CJ, Ma B, Sham YY, Kumar S, Nussinov R. Structured disorder and conformational selection. Proteins Struct. Funct. Bioinform. 2001; 44: 418-427.

94 Shoemaker BA, Portman JJ, Wolynes PG. Speeding molecular recognition by using the folding funnel: the fly-casting mechanism. Proc. Natl. Acad. Sci.U. S. A. 2000; 97: 8868-8873.

95 Zhang X, Bourhis JM, Longhi S, Carsillo T, Buccellato M, Morin B, Canard B, Oglesbee $\mathrm{M}$. Hsp72 recognizes a P binding motif in the measles virus $\mathrm{N}$ protein C-terminus. Virology 2005; 337: 162-174.

96 Couturier M, Buccellato M, Costanzo S, Bourhis JM, Shu Y, Nicaise M, Desmadril M, Flaudrops C, Longhi S, Oglesbee M. High affinity binding between $\mathrm{Hsp70}$ and the C-terminal domain of the measles virus nucleoprotein requires an $\mathrm{Hsp} 40$ co-chaperone. J. Mol. Recognit. 2009; 23: $301-315$

97 Receveur-Bréchot V, Bourhis JM, Uversky VN, Canard B, Longhi S. Assessing protein disorder and induced folding. Proteins Struct. Funct. Bioinform. 2006; 62: 24-45.

98 Uversky VN, Longhi S. Instrumental Analysis of Intrinsically Disordered Proteins: Assessing Structure and Conformation. John Wiley and Sons: Hoboken, New Jersey, 2010.

99 Cellitti SE, Jones DH, Lagpacan L, Hao X, Zhang Q, Hu H, Brittain SM, Brinker A, Caldwell J, Bursulaya B, Spraggon G, Brock A, Ryu Y, Uno T, SchultzPG, Geierstanger BH. In vivo incorporation of unnatural amino acids to probe structure, dynamics, and ligand binding in a large protein by nuclear magnetic resonance spectroscopy. J. Am. Chem. Soc. 2008; 130: 9268-9281.

100 Fleissner MR, Brustad EM, Kalai T, Altenbach C, Cascio D, Peters FB, Hideg K, Peuker S, Schultz PG, Hubbell WL. Site-directed spin labeling of a genetically encoded unnatural amino acid. Proc. Natl. Acad. Sci. U. S. A. 2009; 106: 21637-21642. 